\title{
Estimating Platform Market Power in Two-Sided Markets with an Application to Magazine Advertising
}

\author{
Minjae Song*
}

July $2012^{\dagger}$

\begin{abstract}
In this paper I estimate platform markups in two-sided markets using structural models of platform demand. My models and estimation procedure are applicable to general two-sided market settings where agents on each side care about the presence of agents on the other side and platforms set two membership prices to maximize the sum of profits. Using data on TV magazines in Germany I show that the magazines typically set copy prices below marginal costs and earn profits from selling advertising pages. I also show that mergers are much less anticompetitive than in one-sided markets and could even be welfare enhancing.
\end{abstract}

Keywords: Platform competition, two-sided single-homing, competitive bottleneck, merger simulation

\footnotetext{
*Simon Graduate School of Business, Box 270100, University of Rochester, Rochester, NY 14627-0100. E-mail: minjae.song@simon.rochester.edu. I have benefited from discussions with Paul Ellickson, Marshall Freimer, Daniel Halbheer, Ulrich Kaiser, Jeanine Miklos-Thal, Sanjog Misra, Michael Raith, Kyoungwon Seo, and participants at various conferences and seminars. I especially thank Ulrich Kaiser for providing me with the data used in this paper. All errors are mine.

${ }^{\dagger}$ First version: September 2009.
} 


\section{Introduction}

Two-sided markets are characterized by two groups of agents interacting through intermediaries or platforms. Agents in each group care about the presence of the other group, creating crossgroup externalities, and their economic decisions, such as which platform to join, affect the utility of the other group's agents. Platforms account for these externalities in their strategic decisions such as setting prices. Examples are numerous, including the payment system where merchants

and consumers interact through credit cards, video game systems where game developers and consumers interact through video consoles, print media where advertisers and readers interact through newspapers or magazines, etc. Rysman (2009) provides more examples and an overview on the literature.

In this paper I use structural models of platform demand to estimate platform markups in two-sided markets. Because of the cross-group externalities, prices in two-sided markets can be either higher or lower than profit maximizing prices in one-sided markets. This means that, without considering the two sides simultaneously, researchers will obtain incorrect markups even with consistent demand estimates. The two-sidedness also complicates merger evaluations as higher market power does not necessarily result in higher post-merger prices on either side of the market.

One of challenges in the markup estimation in two-sided markets is tracing a feedback loop that a price perturbation triggers. Suppose two groups, say group A and group B, appreciate the presence of the other group on platforms. When a platform attracts more of group A agents, say because of lowered prices or due to a demand shock, it becomes more attractive to group B agents and attracts more of them. This will make the platform more attractive to group A agents, which, in turn, attracts more group B agents, and so on.

In order to fully trace the feedback loop, I treat a demand system as a system of implicit functions. In this system agents of each side decide which platform to join, given prices, the size of agents from the other side, and other platform attributes. Given this demand system, platforms set two prices to maximize joint profits from both sides. The price elasticity, which is the key component 
in markup estimations, can be numerically computed using properties of implicit functions.

I consider both a two-sided single-homing model and a competitive bottleneck model. In the single-homing model, agents of both groups join only one platform (single-home). In the competitive bottleneck model, one set of agents joins as many platforms as they like (multi-home) while the other set single-homes. Night clubs are an example of the former, where men and women choose one club. Magazine advertising is an example of the latter, where advertisers advertise in multiple magazines while readers choose one magazine in each segment. ${ }^{1}$ In both models I focus on a case where platforms only charge fixed fees for membership.

Numerical simulations show that equilibrium outcomes in the considered models are drastically different from those of the one-sided market. When the cross-group externalities are substantial, platforms may charge below-cost prices to agents on one side to make profit on the other side. Even when prices are above costs, they are not necessarily set on the elastic part of the demand curve. The feedback loop is quantitatively significant such that the price elasticity, when computed without fully tracing it, can be different by more than fifty percent.

For demand estimation I use the generalized method of moments, which is in the same spirit of an estimation procedure widely used in the industrial organization literature (Berry 1994; Berry, Levinsohn, and Pakes, 1995; and many others). Given data on platform prices, market shares and attributes, the agents' mean utilities from each platform are recovered by equating modelpredicted market shares to the observed ones. These mean utilities are assumed to be a linear function of platforms' attributes. Model parameters are estimated by using moment conditions that instrumental variables are not correlated with unobserved platform attributes or demand shocks. There are two important differences from the standard demand estimation. First, there are two demand equations to estimate, one for each side. Second, the size of agents on the other side is included as a platform attribute and this variable is an endogenous variable in addition to the price variable.

\footnotetext{
${ }^{1}$ However, many real world cases have both features. Consider heterosexual dating agencies, another example of the single-homing setting. In the real world men and women may choose multiple dating agencies at the same time.
} 
As an empirical application I use data on TV magazines in Germany and estimate the competitive bottleneck model where advertisers advertise in as many magazines as they want. Two membership fees are the copy price charged to readers and the per-page advertising price charged to advertisers. The number of copies sold and the number of advertising pages are proxies for the number of readers and advertisers joining magazines. The average copy price is about one euro, while the average advertising price per page is close to 30,000 euros. The magazine on average sells about 1.5 million copies in a quarter and has about 250 advertising pages, which means that the advertising revenue is five times as large as the sales revenue.

My results show that magazines typically do not make any profit from selling copies. More than eighty percent of magazines set copy prices below marginal costs, while earning a huge markup, about seventy percent on average, from advertising. Combining the two sides, the joint profit is about 1 million euros on average per quarter. When the advertising side is ignored, the same demand estimates imply seventy percent average markup on the reader side with forty percent of magazines facing inelastic demand.

Taking the advantage of having structural models for both sides, I calculate equilibrium outcomes for hypothetical ownership structures. ${ }^{2}$ Results show that when the market becomes more concentrated, copy prices do not necessarily increase as magazines try to attract more readers. Results also show that larger reader bases resulting from lower copy prices may increase advertisers' demand so much that magazines charge higher advertising prices and attract still more advertisers. This implies that even when a merger increases a publisher's market power on both sides of the market, readers may be better off, or at least less worse off, than predicted by one-sided market models.

There are numerous papers that theoretically analyze various issues related to two-sided markets, of which Rochet and Tirole (2006) provide a thorough review. Among them, my structural models are closely related to the canonical models in Armstrong (2006) but I extend them to a more

\footnotetext{
${ }^{2}$ Finding equilibrium prices is computationally more intensive than for one-sided markets as it requires finding a set of market shares that simultaneously satisfies the demand system for each trial value.
} 
general oligopolistic setting. While Armstrong confines a demand function to Hotelling's framework, I adopt a more general discrete choice framework for consumers' single-homing decisions. Thus, in my models platforms are differentiated products with the presence of the other-side agents as an endogenous attribute.

My models, however, are not applicable to markets where platforms charge usage or pertransaction fees as, for example, in the credit card industry. Rochet and Tirole (2003) develop a model where platforms charge usage fees and Rochet and Tirole (2006) extend it to integrate usage and membership fees in a monopoly platform setting. Although a two-part tariff structure (a fixed membership fee plus a usage fee proportional to the size of the other-side members) is often seen in many industries, it is beyond the scope of my paper. ${ }^{3}$

Empirical research on the two-sided market is relatively scarce but steadily growing. Distinguished from existing empirical studies, my paper brings in two important features of the two-sided market together. The first feature is that agents of each side care about the presence of agents on the other side. This feature is the main factor driving the feedback loop but is suppressed in some studies by assuming that one of the two groups does not care about the presence of the other. For example, Argentesi and Filistrucchi (2007), in studying the Italian newspaper market, assume that readers are indifferent about advertising in newspapers. Although this assumption makes a model more tractable, it misses the essence of the two-sidedness.

The second feature is that platforms set two prices, one for each side. Free membership (or zero price) granted to one group of agents, observed in some of two-sided markets such as the radio industry and the online search engine industry, is part of the platforms' profit maximization behaviors. However, this zero price is often taken as an exogenous constraint in modeling platform behaviors. Examples include Rysman (2004) on the Yellow Pages and Jeziorski (2011) on the radio industry. As far as I know, Kaiser and Wright (2006) is the only structural empirical paper

\footnotetext{
${ }^{3} \mathrm{~A}$ well-known proposition in Armstrong (2006) shows that a continuum of equilibria exists when platforms compete in the two-part tariff. Weyl and White (2010) propose a new equilibrium concept to circumvent this problem.
} 
that has both features together, but their model is only applicable to a duopoly in the symmetric equilibrium.

There are also empirical studies that test predictions from theoretical models using reducedform regressions. For example, Jin and Rysman (2010) use data from baseball card conventions and test whether the conventions' pricing behaviors are consistent with the single-homing model in Armstrong (2006) . Chandra and Collard-Wexler (forthcoming) develop a two-sided market model in the Hotelling framework, derive predictions on post-merger price changes, and test them using data from the Canadian newspaper market.

The paper is organized as follows: Section 2 presents two models of the two-sided market, followed by an estimation procedure in section 3. Section 4 presents simulation results and section 5 presents empirical results. Section 6 concludes.

\section{Models}

\subsection{Two-Sided Single-Homing Model}

There are two groups of agents, groups A and B, and each group may like or dislike the presence of the other group on platforms. There are $J$ platforms competing to attract agents from both sides. Assume for exogenous reasons that each agent chooses to join a single platform.

If platform $j$ attracts $s_{j}^{A}$ and $s_{j}^{B}$ portions of the two groups, agents' utilities are

$$
\begin{aligned}
& u_{i j}^{A}=\mu_{j}^{A}+\alpha^{A} s_{j}^{B}-\lambda^{A} p_{j}^{A}+\xi_{j}^{A}+\varepsilon_{i j}^{A} \\
& u_{i j}^{B}=\mu_{j}^{B}+\alpha^{B} s_{j}^{A}-\lambda^{B} p_{j}^{B}+\xi_{j}^{B}+\varepsilon_{i j}^{B}
\end{aligned}
$$

where $\mu_{j}^{A}$ and $\mu_{j}^{B}$ denote the mean utilities apart from prices and the size of the other group, $p_{j}^{A}$ and $p_{j}^{B}$ prices charged to each group, $\xi_{j}^{A}$ and $\xi_{j}^{B}$ qualities and/or demand shocks that the agents observe but researchers do not, and $\varepsilon_{i j}^{A}$ and $\varepsilon_{i j}^{B}$ idiosyncratic taste shocks. $\alpha^{A}$ and $\alpha^{B}$ measure 
the (dis)utility of interacting with agents of the other group and $\lambda^{A}$ and $\lambda^{B}$ the disutility of price. Consumers may choose the outside option of joining no platform and receive zero mean utility and an idiosyncratic shock.

Assuming $\varepsilon_{i j}$ is an i.i.d. type I extreme value, market share functions for platform $j$ are

$$
\begin{aligned}
S_{j}^{A}\left(\mathbf{p}^{A}, \mathbf{s}^{B}, \boldsymbol{\xi}^{A} \mid \Omega\right) & =\frac{\exp \left(\mu_{j}^{A}+\alpha^{A} s_{j}^{B}-\lambda^{A} p_{j}^{A}+\xi_{j}^{A}\right)}{1+\sum_{m=1}^{J} \exp \left(\mu_{m}^{A}+\alpha^{A} s_{m}^{B}-\lambda^{A} p_{m}^{A}+\xi_{m}^{A}\right)} \\
S_{j}^{B}\left(\mathbf{p}^{B}, \mathbf{s}^{A}, \boldsymbol{\xi}^{B} \mid \Omega\right) & =\frac{\exp \left(\mu_{j}^{B}+\alpha^{B} s_{j}^{A}-\lambda^{B} p_{j}^{B}+\xi_{j}^{B}\right)}{1+\sum_{m=1}^{J} \exp \left(\mu_{m}^{B}+\alpha^{B} s_{m}^{A}-\lambda^{B} p_{m}^{B}+\xi_{m}^{B}\right)}
\end{aligned}
$$

where $\Omega=\left(\boldsymbol{\mu}^{A}, \boldsymbol{\mu}^{B}, \lambda^{A}, \lambda^{B}, \alpha^{A}, \alpha^{B}\right)$. These equations show how the two groups of agents interact through platforms. Notice that $s_{j}^{B}$ enters in $S_{j}^{A}$ and $s_{j}^{A}$ in $S_{j}^{B}$. Any events affecting the membership decisions of group A agents affect the decisions of group B agents as well. But the effect does not end here. Group B agents' membership decisions in turn affect group A agents' decisions, which also in turn affects group B agents' decisions, and so on.

Let the share equations equate observed market shares such that

$$
\begin{aligned}
& s_{j}^{A}=S_{j}^{A}\left(\mathbf{p}^{A}, \mathbf{s}^{B}, \boldsymbol{\xi}^{A} \mid \Omega\right) \equiv \frac{\exp \left(\mu_{j}^{A}+\alpha^{A} s_{j}^{B}-\lambda^{A} p_{j}^{A}+\xi_{j}^{A}\right)}{1+\sum_{m=1}^{J} \exp \left(\mu_{m}^{A}+\alpha^{A} s_{m}^{B}-\lambda^{A} p_{m}^{A}+\xi_{m}^{A}\right)} \\
& s_{j}^{B}=S_{j}^{B}\left(\mathbf{p}^{B}, \mathbf{s}^{A}, \boldsymbol{\xi}^{B} \mid \Omega\right) \equiv \frac{\exp \left(\mu_{j}^{B}+\alpha^{B} s_{j}^{A}-\lambda^{B} p_{j}^{B}+\xi_{j}^{B}\right)}{1+\sum_{m=1}^{J} \exp \left(\mu_{m}^{B}+\alpha^{B} s_{m}^{A}-\lambda^{B} p_{m}^{B}+\xi_{m}^{B}\right)}
\end{aligned}
$$

for $j=1, \ldots, J$. Let $\mathbf{B}$ be a nonempty, closed, bounded, and convex subset of $\mathbf{R}^{2 J}$. Since $\mathbf{s}=$ $\left(\mathbf{s}^{A}, \mathbf{s}^{B}\right) \in \mathbf{B}$ and the share functions are continuous, we know from Brouwer's fixed point theorem that, given $\mathbf{p}=\left(\mathbf{p}^{A}, \mathbf{p}^{B}\right)$, there exists at least one set of market shares that satisfies all of the $2 \times J$ equations at the same time. Thus, I can treat observed market shares, s, as one of those sets.

Notice that there could be multiple sets of market shares that satisfy the equations given the same prices. However, this multiplicity does not present an additional challenge in estimating the model. No matter how many equilibria there may be, I do observe one of them in each market. 
Given this observation, all I need for identification is instrumental variables that are not correlated with demand shocks but correlated with the other side's market shares. This even means that I do not need to use both sides to consistently estimate demand for one side. ${ }^{4}$

It is worth comparing multiplicity in the two-sided market model with multiplicity in the empirical game literature where multiple equilibria make model estimation more challenging. Consider a static incomplete information entry game with two firms. Firm 1's probability of entry is a function of firm 2's probability of entry, and vice versa, and these probability functions look similar to equations (5) and (6) with the type I extreme value distribution assumption on the idiosyncratic shock. The key difference is that researchers do not observe the entry probability and should compute it as a solution to the game. However, it is not guaranteed that they obtain the same equilibrium in all markets.

\subsection{Competitive Bottleneck Model}

In the competitive bottleneck model, while one group, group A, deals with a single platform (singlehomes), the other group, group B, deals with multiple platforms (multi-homes). This is a situation where group B puts more weight on the network-benefits of being in contact with the widest population of group A consumers than it does on the costs of dealing with more than one platform. An example often used for this model is media advertising. Group A agents are readers who care about media content and may or may not like advertising. The other group agents are advertisers who want to reach as many readers as possible.

Following Armstrong (2006) I assume that a group B agent makes a decision to join one platform independently from its decision to join another as long as its net benefit is positive. In this sense there is no direct competition between platforms to attract group B agents and each platform acts as a monopolist towards them. For group A agents I use the same utility function used in the single-homing model except that I use the number of group B agents instead of their

\footnotetext{
${ }^{4}$ However, multiple equilibria comes into play in counterfactual exercises.
} 
share such that

$$
u_{i j}^{A}=\mu_{j}^{A}+\alpha^{A} n_{j}^{B}-\lambda^{A} p_{j}^{A}+\xi_{j}^{A}+\varepsilon_{i j}^{A}
$$

where $n_{j}^{B}$ denotes the number of group B agents on platform $j$. Thus, platform $j^{\prime} s$ market share function for group $A$ is

$$
S_{j}^{A}\left(\mathbf{p}^{A}, \mathbf{n}^{B}, \boldsymbol{\xi}^{A} \mid \Omega\right)=\frac{\exp \left(\mu_{j}^{A}+\alpha^{A} n_{j}^{B}-\lambda^{A} p_{j}^{A}+\xi_{j}^{A}\right)}{1+\sum_{m=1}^{J} \exp \left(\mu_{m}^{A}+\alpha^{A} n_{m}^{B}-\lambda^{A} p_{m}^{A}+\xi_{m}^{A}\right)}
$$

In the single-homing model I assume that agents care about which platform attracts more agents of the other side regardless of their numbers. For example, in choosing a night club men and women care about which night club attracts the most members of the opposite sex, not its absolute number. In the competitive bottleneck, on the other hand, I assume that single-homing agents, say group A agents, pay attention to the actual numbers of multi-homing agents on platforms. This means that in the example of media advertising, the audience cares about the absolute amount of advertising. This distinction is not relevant in (most theoretical) models where the group size is normalized to 1 .

Let $\alpha_{i}^{B}$ denote a group B agent type which is i.i.d. from $G\left(\alpha^{B} \mid \theta\right)$ and $\omega_{j}$ be a platformspecific quality perceived by group B agents. I assume that group B agents receive utility only from interacting with group A agents and that their utility of interacting with one agent of group A on platform $j$ is $\alpha_{i}^{B} \omega_{j}$. This means that the same number of group A agents may generate different values for group B agents depending on their types and which platform they are on. In the media advertising case, this implies that the advertising profitability for the same number of readers is different among advertisers and among platforms.

Given the fixed membership fee, $p_{j}^{B}$, a type- $\alpha_{i}^{B}$ agent's utility of joining platform $j$ is

$$
u_{i j}^{B}=\alpha_{i}^{B} \omega_{j} n_{j}^{A}-p_{j}^{B}
$$


and she will join this platform as long as $\alpha_{i}^{B} \omega_{j} n_{j}^{A} \geq p_{j}^{B}$. Suppose platforms only know the distribution of $\alpha_{i}^{B}$. Since each group B agent is ex ante identical, a given platform will charge the same price $p_{j}^{B}$ and the number of group B agents joining platform $j$ is determined by

$$
N_{j}^{B}\left(\mathbf{p}^{B}, \mathbf{n}^{A} \mid \Omega\right)=\left(1-G\left(\frac{p_{j}^{B}}{\omega_{j} n_{j}^{A}} \mid \theta\right)\right) M^{B}
$$

where $M^{B}$ is the total number of group B agents.

Similarly as in the two-sided single-homing model, I equate observed shares to the share equations such that

$$
\begin{aligned}
s_{j}^{A} & =\frac{\exp \left(\mu_{j}^{A}+\alpha^{A} s_{j}^{B} M^{B}-\lambda^{A} p_{j}^{A}+\xi_{j}^{A}\right)}{1+\sum_{m=1}^{J} \exp \left(\mu_{m}^{A}+\alpha^{A} s_{m}^{B} M^{B}-\lambda^{A} p_{m}^{A}+\xi_{m}^{A}\right)} \\
s_{j}^{B} & =\frac{N_{j}^{B}\left(\mathbf{p}^{B}, \mathbf{s}^{A} \mid \Omega\right)}{M^{B}} \equiv\left(1-G\left(\frac{p_{j}^{B}}{\omega_{j} s_{j}^{A} M^{A}} \mid \theta\right)\right)
\end{aligned}
$$

for $j=1, \ldots, J$, and treat observed market shares, $\mathbf{s}$, as equilibrium market shares. ${ }^{5}$ Notice that I use $s_{j}^{A} M^{A}$ and $s_{j}^{B} M^{B}$ instead of $n_{j}^{A}$ and $n_{j}^{B}$ where $M^{A}$ is the total number of group A agents.

\subsection{Elasticity and Markup}

To compute the price elasticity I re-write the share functions as a system of implicit functions. In the two-sided single-homing model, let $F_{1}^{A}, F_{1}^{B}, F_{2}^{A}, F_{2}^{B}, \ldots, F_{J}^{A}, F_{J}^{B}: \mathbf{R}^{2 J+2 J} \rightarrow \mathbf{R}^{1}$ be

$$
\begin{aligned}
F_{j}^{A}(\mathbf{s}, \mathbf{p}) & \equiv \frac{\exp \left(\mu_{j}^{A}+\alpha^{A} s_{j}^{B}-\lambda^{A} p_{j}^{A}+\xi_{j}^{A}\right)}{1+\sum_{m=1}^{J} \exp \left(\mu_{m}^{A}+\alpha^{A} s_{m}^{B}-\lambda^{A} p_{m}^{A}+\xi_{m}^{A}\right)}-s_{j}^{A}=0 \\
F_{j}^{B}(\mathbf{s}, \mathbf{p}) & \equiv \frac{\exp \left(\mu_{j}^{B}+\alpha^{B} s_{j}^{A}-\lambda^{B} p_{j}^{B}+\xi_{j}^{B}\right)}{1+\sum_{m=1}^{J} \exp \left(\mu_{m}^{B}+\alpha^{B} s_{m}^{A}-\lambda^{B} p_{m}^{B}+\xi_{m}^{B}\right)}-s_{j}^{B}=0
\end{aligned}
$$

\footnotetext{
${ }^{5}$ See the appendix for alternative utility specifications for multi-homing agents.
} 
for $j=1, \ldots, J$ where $\mathbf{s}$ are endogenous variables and $\mathbf{p}$ are exogenous variables. In the competitive bottleneck model, let $F_{1}^{A}, F_{1}^{B}, F_{2}^{A}, F_{2}^{B}, \ldots, F_{J}^{A}, F_{J}^{B}: \mathbf{R}^{2 J+2 J} \rightarrow \mathbf{R}^{1}$ be

$$
\begin{aligned}
F_{j}^{A}(\mathbf{s}, \mathbf{p}) & \equiv \frac{\exp \left(\mu_{j}^{A}+\alpha^{A} s_{j}^{B} M^{B}-\lambda^{A} p_{j}^{A}+\xi_{j}^{A}\right)}{1+\sum_{m=1}^{J} \exp \left(\mu_{m}^{A}+\alpha^{A} s_{m}^{B} M^{B}-\lambda^{A} p_{m}^{A}+\xi_{m}^{A}\right)}-s_{j}^{A}=0 \\
F_{j}^{B}(\mathbf{s}, \mathbf{p}) & \equiv\left(1-G\left(\frac{p_{j}^{B}}{\omega_{j} s_{j}^{A} M^{A}} \mid \theta\right)\right)-s_{j}^{B}=0
\end{aligned}
$$

for $j=1, \ldots, J$.

An underlying assumption is that platforms control prices and market shares are determined by the specified demand functions. This implies that agents treat the number of participants from the other side as a platform attribute and platforms expect agents to behave in this way. This excludes agents coordinating their membership decisions with agents on the other side. This is a reasonable assumption in many empirical settings, including media advertising where the number of agents is large. ${ }^{6}$

Since these functions are continuously differentiable, I can use the implicit function theorem

\footnotetext{
${ }^{6}$ Rochet and Tirole (2006) also treat the coordinated membership decision case as a rare case and exclude it from their analysis. See section 4 in Rochet and Tirole (2006).
} 
to compute the price elasticity. For a price change by platform $j$

$$
\begin{aligned}
\left(\begin{array}{cc}
\partial s_{1}^{A} / \partial p_{j}^{A} & \partial s_{1}^{A} / \partial p_{j}^{B} \\
\partial s_{1}^{B} / \partial p_{j}^{A} & \partial s_{1}^{B} / \partial p_{j}^{B} \\
\vdots & \vdots \\
\partial s_{J}^{A} / \partial p_{j}^{A} & \partial s_{J}^{A} / \partial p_{j}^{B} \\
\partial s_{J}^{B} / \partial p_{j}^{A} & \partial s_{J}^{B} / \partial p_{j}^{B}
\end{array}\right)=-\left(\begin{array}{ccccc}
\partial F_{1}^{A} / \partial s_{1}^{A} & \partial F_{1}^{A} / \partial s_{1}^{B} & \cdots & \partial F_{1}^{A} / \partial s_{J}^{A} & \partial F_{1}^{A} / \partial s_{J}^{B} \\
\partial F_{1}^{B} / \partial s_{1}^{A} & \partial F_{1}^{B} / \partial s_{1}^{B} & \cdots & \partial F_{1}^{B} / \partial s_{J}^{A} & \partial F_{1}^{B} / \partial s_{J}^{B} \\
\vdots & \vdots & \ddots & \vdots & \vdots \\
\partial F_{J}^{A} / \partial s_{1}^{A} & \partial F_{J}^{A} / \partial s_{1}^{B} & \cdots & \partial F_{J}^{A} / \partial s_{J}^{A} & \partial F_{J}^{A} / \partial s_{J}^{B} \\
\partial F_{J}^{B} / \partial s_{1}^{A} & \partial F_{J}^{B} / \partial s_{1}^{B} & \cdots & \partial F_{J}^{B} / \partial s_{J}^{A} & \partial F_{J}^{B} / \partial s_{J}^{B}
\end{array}\right) \\
\times\left(\begin{array}{ccc}
\partial F_{1}^{A} / \partial p_{j}^{A} & \partial F_{1}^{A} / \partial p_{j}^{B} \\
\partial F_{1}^{B} / \partial p_{j}^{A} & \partial F_{1}^{B} / \partial p_{j}^{B} \\
\vdots & \vdots \\
\partial F_{J}^{A} / \partial p_{j}^{A} & \partial F_{J}^{A} / \partial p_{j}^{B} \\
\partial F_{J}^{B} / \partial p_{j}^{A} & \partial F_{J}^{B} / \partial p_{j}^{B}
\end{array}\right),
\end{aligned}
$$

provided that the inverse matrix is non-singular. ${ }^{7}$

Suppose there are two platforms. For platform 1's price change in the two-sided singlehoming model,

$$
\begin{aligned}
& \left(\begin{array}{cccc}
\partial F_{1}^{A} / \partial s_{1}^{A} & \partial F_{1}^{A} / \partial s_{1}^{B} & \partial F_{1}^{A} / \partial s_{2}^{A} & \partial F_{1}^{A} / \partial s_{2}^{B} \\
\partial F_{1}^{B} / \partial s_{1}^{A} & \partial F_{1}^{B} / \partial s_{1}^{B} & \partial F_{1}^{B} / \partial s_{2}^{A} & \partial F_{1}^{B} / \partial s_{2}^{B} \\
\partial F_{2}^{A} / \partial s_{1}^{A} & \partial F_{2}^{A} / \partial s_{1}^{B} & \partial F_{2}^{A} / \partial s_{2}^{A} & \partial F_{2}^{A} / \partial s_{2}^{B} \\
\partial F_{2}^{B} / \partial s_{1}^{A} & \partial F_{2}^{B} / \partial s_{1}^{B} & \partial F_{2}^{B} / \partial s_{2}^{A} & \partial F_{2}^{B} / \partial s_{2}^{B}
\end{array}\right) \\
& =\left(\begin{array}{cccc}
\alpha^{B} s_{1}^{B}\left(1-s_{1}^{B}\right) & -1 & -\alpha^{B} s_{1}^{B} s_{2}^{B} & -\alpha^{A} s_{1}^{A} s_{2}^{A} \\
0 & -\alpha^{A} s_{1}^{A}\left(1-s_{1}^{A}\right) & -1 & 0 \\
-\alpha^{B} s_{1}^{B} s_{2}^{B} & 0 & \alpha^{B} s_{2}^{B}\left(1-s_{2}^{B}\right) & -1
\end{array}\right)^{-1} s_{2}^{A}\left(1-s_{2}^{A}\right)
\end{aligned}
$$

\footnotetext{
${ }^{7}$ Note that this is still a valid formula when platforms are constrained to grant free access to one side of the market.
} 
and

$$
\left(\begin{array}{cc}
\partial F_{1}^{A} / \partial p_{1}^{A} & \partial F_{1}^{A} / \partial p_{1}^{B} \\
\partial F_{1}^{B} / \partial p_{1}^{A} & \partial F_{1}^{B} / \partial p_{1}^{B} \\
\partial F_{2}^{A} / \partial p_{1}^{A} & \partial F_{2}^{A} / \partial p_{1}^{B} \\
\partial F_{2}^{B} / \partial p_{1}^{A} & \partial F_{2}^{B} / \partial p_{1}^{B}
\end{array}\right)=\left(\begin{array}{cc}
-\lambda^{A} s_{1}^{A}\left(1-s_{1}^{A}\right) & 0 \\
0 & -\lambda^{B} s_{1}^{B}\left(1-s_{1}^{B}\right) \\
\lambda^{A} s_{1}^{A} s_{2}^{A} & 0 \\
0 & \lambda^{B} s_{1}^{B} s_{2}^{B}
\end{array}\right)
$$

In the competitive bottleneck model,

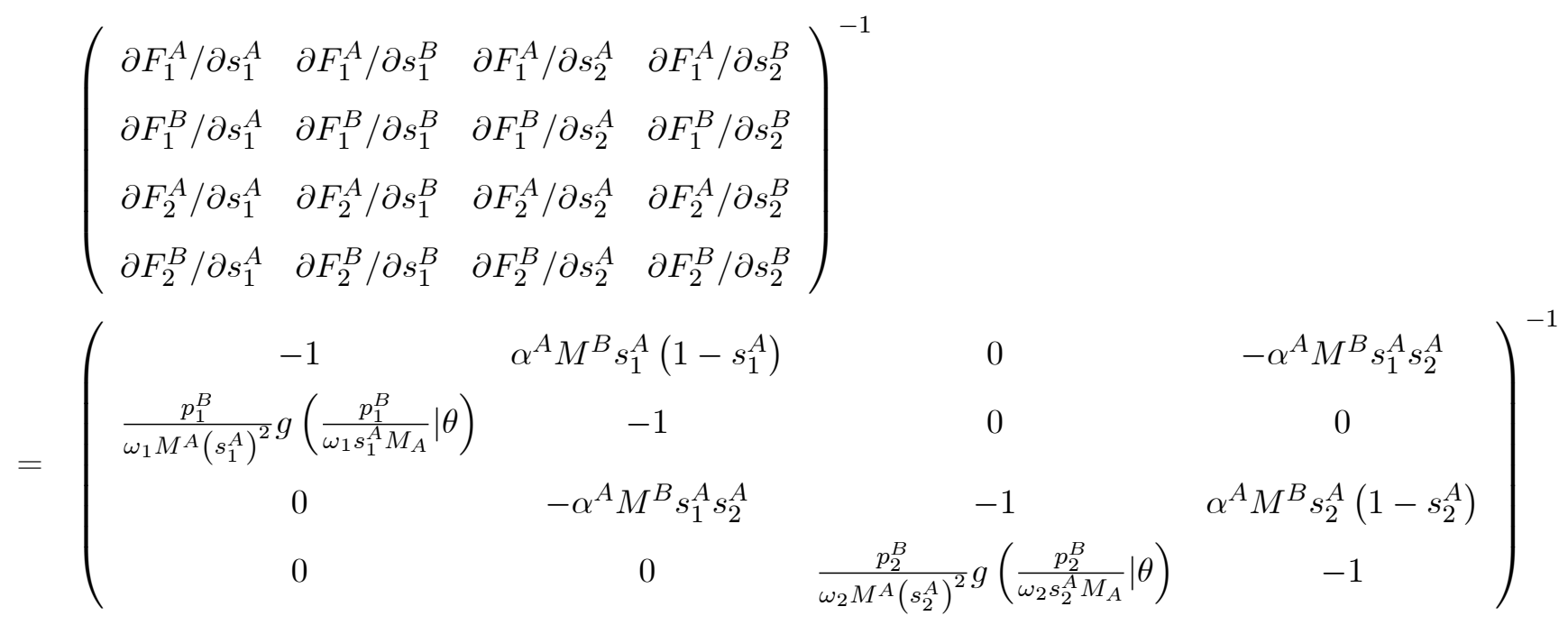

and

$$
\left(\begin{array}{cc}
\partial F_{1}^{A} / \partial p_{1}^{A} & \partial F_{1}^{A} / \partial p_{1}^{B} \\
\partial F_{1}^{B} / \partial p_{1}^{A} & \partial F_{1}^{B} / \partial p_{1}^{B} \\
\partial F_{2}^{A} / \partial p_{1}^{A} & \partial F_{2}^{A} / \partial p_{1}^{B} \\
\partial F_{2}^{B} / \partial p_{1}^{A} & \partial F_{2}^{B} / \partial p_{1}^{B}
\end{array}\right)=\left(\begin{array}{cc}
-\lambda^{A} s_{1}^{A}\left(1-s_{1}^{A}\right) & 0 \\
0 & \frac{-1}{\omega_{1} s_{1}^{A} M^{A}} g\left(\frac{p_{1}^{B}}{\omega_{1} s_{1}^{A} M^{A}} \mid \theta\right) \\
\lambda^{A} s_{1}^{A} s_{2}^{A} & 0 \\
0 & 0
\end{array}\right)
$$

where $g($.$) is the pdf of the group B agent's type distribution.$

Notice that, were it not for the two-sidedness, the second term in (10) multiplied by the price-share ratio would be the price elasticity and that all cross-group terms, $\left(\partial F_{k}^{A} / \partial p_{j}^{B}\right.$ and $\partial F_{k}^{B} / \partial p_{j}^{A}$, for $\left.k=1, \ldots, J\right)$ would be zero. Moreover, in the competitive bottleneck model the cross-price elasticity on the agent $\mathrm{B}$ side $\left(\partial F_{r}^{B} / \partial p_{j}^{B}, r \neq j\right)$ would also be zero. Notice also that the literature usually approximates price elasticity by considering only the direct impact of a price 
change on $s_{j}^{A}$ and $s_{j}^{B}$. That is,

$$
\begin{aligned}
\frac{\partial s_{j}^{A}}{\partial p_{j}^{A}} & \approx \frac{\partial S_{j}^{A}(.)}{\partial p_{j}^{A}} \\
\frac{\partial s_{j}^{B}}{\partial p_{j}^{A}} & \approx \sum_{k=1}^{J} \frac{\partial S_{j}^{B}(.)}{\partial s_{k}^{A}} \frac{\partial S_{k}^{A}(.)}{\partial p_{j}^{A}} \\
\frac{\partial s_{j}^{A}}{\partial p_{j}^{B}} & \approx \sum_{k=1}^{J} \frac{\partial S_{j}^{A}(.)}{\partial s_{k}^{B}} \frac{\partial S_{k}^{B}(.)}{\partial p_{j}^{B}}
\end{aligned}
$$

where $S^{A}($.$) and S^{B}($.$) are defined by equations (3) and (4) .^{8}$

As an example, let $\alpha^{A}=\alpha^{B}=1, \lambda^{A}=\lambda^{B}=2, s_{1}^{A}=s_{1}^{B}=s_{2}^{A}=s_{2}^{B}=0.3, \omega_{1}=\omega_{2}=1$, and $p_{1}^{B}=p_{2}^{B}=1$. In the two-sided single-homing model

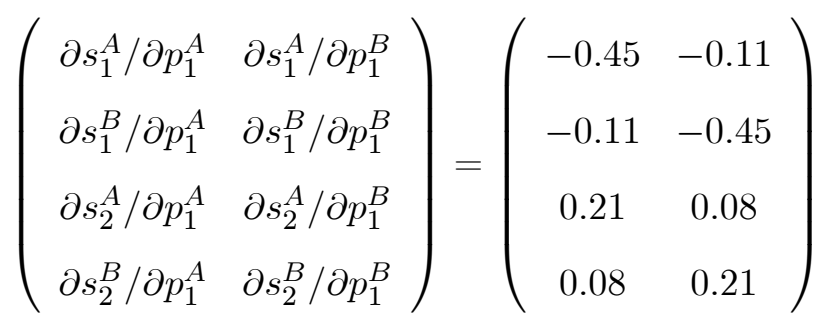

while

$$
\left(\begin{array}{ll}
\partial F_{1}^{A} / \partial p_{1}^{A} & \partial F_{1}^{A} / \partial p_{1}^{B} \\
\partial F_{1}^{B} / \partial p_{1}^{A} & \partial F_{1}^{B} / \partial p_{1}^{B} \\
\partial F_{2}^{A} / \partial p_{1}^{A} & \partial F_{2}^{A} / \partial p_{1}^{B} \\
\partial F_{2}^{B} / \partial p_{1}^{A} & \partial F_{2}^{B} / \partial p_{1}^{B}
\end{array}\right)=\left(\begin{array}{cc}
-0.42 & 0 \\
0 & -0.42 \\
0.18 & 0 \\
0 & 0.18
\end{array}\right)
$$

\footnotetext{
${ }^{8}$ In section 4 I numerically evaluate the accuracy of this approximation.
} 
In the competitive bottleneck model

$$
\left(\begin{array}{cc}
\partial s_{1}^{A} / \partial p_{1}^{A} & \partial s_{1}^{A} / \partial p_{1}^{B} \\
\partial s_{1}^{B} / \partial p_{1}^{A} & \partial s_{1}^{B} / \partial p_{1}^{B} \\
\partial s_{2}^{A} / \partial p_{1}^{A} & \partial s_{2}^{A} / \partial p_{1}^{B} \\
\partial s_{2}^{B} / \partial p_{1}^{A} & \partial s_{2}^{B} / \partial p_{1}^{B}
\end{array}\right)=\left(\begin{array}{cc}
-0.50 & -0.05 \\
-0.32 & -0.22 \\
0.24 & 0.02 \\
0.16 & 0.02
\end{array}\right)
$$

while

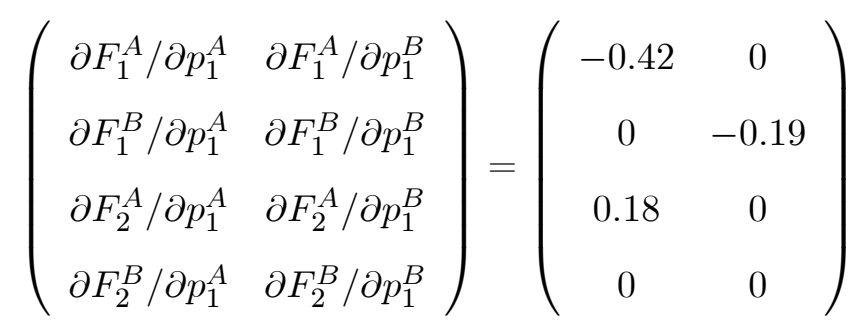

This example demonstrates that the cross-group price elasticity is non-zero in two-sided markets. When a platform changes its price on one side, it not only affects its market share on the other side but also affects its rival platform's market share on the other side. It also shows that the cross-price elasticity among platforms $\left(\partial s_{2}^{B} / \partial p_{1}^{B}\right)$ is not zero in the competitive bottleneck model. This implies that, although a group B agent makes a decision to join one platform independently from its decision to join another, a platform's pricing is not purely monopolistic due to the crossgroup interaction.

Notice that the sign of the cross-group elasticity depends on that of the marginal utility of the cross-group interaction, i.e., $\alpha^{A}$ and $\alpha^{B}$. For example, if both $\alpha^{A}$ and $\alpha^{B}$ are negative in the two-sided single-homing model, $\partial s_{1}^{A} / \partial p_{1}^{B}$ and $\partial s_{1}^{B} / \partial p_{1}^{A}$ become positive and $\partial s_{2}^{A} / \partial p_{1}^{B}$ and $\partial s_{2}^{B} / \partial p_{1}^{A}$ negative. In the competitive bottleneck model, if $\alpha^{A}$ is negative, $\partial s_{1}^{A} / \partial p_{1}^{B}$ becomes positive and both $\partial s_{2}^{A} / \partial p_{1}^{B}$ and $\partial s_{2}^{B} / \partial p_{1}^{B}$ become negative. ${ }^{9}$ It is particularly interesting that $\partial s_{2}^{B} / \partial p_{1}^{B}$ becomes negative when group A agents dislike the presence of group B agents. The negative $\partial s_{2}^{B} / \partial p_{1}^{B}$ means that platforms gain clients when rivals reduce prices.

\footnotetext{
${ }^{9}$ It is reasonable to assume that group B agents always like to interact with group A agents.
} 
I use demand estimates and the profit maximization conditions to recover platforms' operating costs. Platform $j$ maximizes its profit by setting membership prices for the two groups, $p_{j}^{A}$ and $p_{j}^{B}$. Assuming the constant marginal cost, platform $j$ 's profit is

$$
\pi_{j}=\left(p_{j}^{A}-c_{j}^{A}\right) s_{j}^{A} M^{A}+\left(p_{j}^{B}-c_{j}^{B}\right) s_{j}^{B} M^{B}
$$

where $M_{A}$ and $M_{B}$ denote the total number of agents for each group respectively. The profit maximizing first order conditions are

$$
\begin{aligned}
& \frac{\partial \pi_{j}}{\partial p_{j}^{A}}=s_{j}^{A} M^{A}+\left(p_{j}^{A}-c_{j}^{A}\right) \frac{\partial s_{j}^{A}}{\partial p_{j}^{A}} M^{A}+\left(p_{j}^{B}-c_{j}^{B}\right) \frac{\partial s_{j}^{B}}{\partial p_{j}^{A}} M^{B}=0 \\
& \frac{\partial \pi_{j}}{\partial p_{j}^{B}}=s_{j}^{B} M^{B}+\left(p_{j}^{B}-c_{j}^{B}\right) \frac{\partial s_{j}^{B}}{\partial p_{j}^{B}} M^{B}+\left(p_{j}^{A}-c_{j}^{A}\right) \frac{\partial s_{j}^{A}}{\partial p_{j}^{B}} M^{A}=0
\end{aligned}
$$

where all the share derivatives are computed by (10). The two marginal costs should be searched simultaneously such that the two conditions are satisfied at the same time for each platform. ${ }^{10}$

Re-arranging equations (12) and (13) gives

$$
\begin{aligned}
\left(p_{j}^{A}-c_{j}^{A}\right) & =-p_{j}^{A}\left(\frac{\partial s_{j}^{A}}{\partial p_{j}^{A}} \frac{p_{j}^{A}}{s_{j}^{A}}\right)^{-1}-\left(p_{j}^{B}-c_{j}^{B}\right)\left(\frac{\partial s_{j}^{B}}{\partial p_{j}^{A}} \frac{p_{j}^{A}}{s_{j}^{B}}\right)\left(\frac{\partial s_{j}^{A}}{\partial p_{j}^{A}} \frac{p_{j}^{A}}{s_{j}^{A}}\right)^{-1} \frac{n_{j}^{B}}{n_{j}^{A}} \\
\left(p_{j}^{B}-c_{j}^{B}\right) & =-p_{j}^{B}\left(\frac{\partial s_{j}^{B}}{\partial p_{j}^{B}} \frac{p_{j}^{B}}{s_{j}^{B}}\right)^{-1}-\left(p_{j}^{A}-c_{j}^{A}\right)\left(\frac{\partial s_{j}^{A}}{\partial p_{j}^{B}} \frac{p_{j}^{B}}{s_{j}^{A}}\right)\left(\frac{\partial s_{j}^{B}}{\partial p_{j}^{B}} \frac{p_{j}^{B}}{s_{j}^{B}}\right)^{-1} \frac{n_{j}^{A}}{n_{j}^{B}}
\end{aligned}
$$

These equations show that a platform's markup from one side is a function of (1) the own-price elasticity, (2) its markup from the other side, (3) the cross-group price elasticity divided by the own-price elasticity and (4) the relative group size.

Note that Armstrong (2006) uses $C\left(n_{j}^{A}, n_{j}^{B}\right)=c_{j} n_{j}^{A} n_{j}^{B}$ in showing that the equilibrium $n_{j}^{B}$ is determined regardless of the size of the platform's readership, $n_{j}^{A}$. This means that advertisers do not gain or lose when the market for readers becomes more competitive. However, this cost

\footnotetext{
${ }^{10}$ This search process involves numerical computation of the share derivatives at each set of trial values.
} 
function is not appropriate in an empirical setting because of an overidentification problem: the number of unknown variables should be the same as the number of equations to satisfy.

\section{Estimation}

In the two-sided single-homing model I take the log of equations (5) and (6), and estimate

$$
\begin{aligned}
& \log \left(s_{j}^{A}\right)-\log \left(1-\sum_{j=1}^{J} s_{j}^{A}\right)=\mu_{j}^{A}+\alpha^{A} s_{j}^{B}-\lambda^{A} p_{j}^{A}+\xi_{j}^{A} \\
& \log \left(s_{j}^{B}\right)-\log \left(1-\sum_{j=1}^{J} s_{j}^{B}\right)=\mu_{j}^{B}+\alpha^{B} s_{j}^{A}-\lambda^{B} p_{j}^{B}+\xi_{j}^{B}
\end{aligned}
$$

$j=1, \ldots, J$. The model parameters are $\Omega=\left(\boldsymbol{\mu}^{A}, \boldsymbol{\mu}^{B}, \lambda^{A}, \lambda^{B}, \alpha^{A}, \alpha^{B}\right)$. Let platform quality be $\delta_{j}^{A}=\mu_{j}^{A}+\alpha^{A} s_{j}^{B}-\lambda^{A} p_{j}^{A}+\xi_{j}^{A}$ and define $\delta_{j}^{B}$ similarly. In order to estimate these equations, the unique platform quality should exist for each side, given data on prices and market shares. One can use the same logic used in Berry (1994) to show this is true for both equations.

These demand equations can be consistently estimated by the GMM with instrumental variables for the price variable and the other group's share variable, $s_{j}^{B}$ in equation (16) and $s_{j}^{A}$ in equation (17). The latter is an additional endogenous variable that is correlated not only with the same side $\xi_{j}$ but also with the other side $\xi_{j}$. The consistency does not require estimating both equations at the same time as long as each side has valid instruments for the endogenous variables. The efficiency, however, may improve by simultaneously estimating them.

Consumer heterogeneity can be added to the model by allowing $\left(\alpha^{A}, \alpha^{B}, \lambda^{A}, \lambda^{B}\right)$ to be random coefficients with respect to agents. For example, for agents in group A

$$
\begin{aligned}
\alpha_{i}^{A} & =l^{A}+\sigma^{A} v_{i} \\
\lambda_{i}^{A} & =m^{A}+\tau^{A} \varpi_{i}
\end{aligned}
$$


where $v$ and $\varpi$ are i.i.d. standard normal. The same logic used in BLP can be used to show the existence and uniqueness of $\left(\boldsymbol{\delta}^{A}, \boldsymbol{\delta}^{B}\right)$ and contraction mapping can be used to estimate them. The model parameters are now $\widetilde{\Omega}=\left(\mu_{j}^{A}, \mu_{j}^{B}, l^{A}, l^{B}, m^{A}, m^{B}, \sigma^{A}, \sigma^{B}, \tau^{A}, \tau^{B}\right) \cdot{ }^{11}$

In the competitive bottleneck model the demand equation for group $A$ agents is

$$
\log \left(s_{j}^{A}\right)-\log \left(1-\sum_{j=1}^{J} s_{j}^{A}\right)=\mu_{j}^{A}+\alpha^{A} n_{j}^{B}-\lambda^{A} p_{j}^{A}+\xi_{j}^{A}
$$

For group $B$ the platform quality, $\boldsymbol{\omega}$, should be first recovered by inverting equation (9), given value of $\theta$ and data on $\left(n_{j}^{B}, n_{j}^{A}, p_{j}^{B}, M_{B}\right)$. Since equation (9) is a strictly monotonic function of $\omega_{j}$, there exists unique $\omega_{j}$ for each platform. Assuming that $\omega_{j}$ is a function of platforms' non-price characteristics, the demand equation for group $B$ agents is

$$
\omega_{j t}=h\left(\mathbf{x}_{j t} \mid \beta^{B}\right)
$$

The model parameters are $\Omega=\left(\mu_{j}^{A}, \lambda^{A}, \alpha^{A}, \beta^{B}, \theta\right)$, and they can be consistently estimated by using the GMM. Similarly to the single-homing case, consumer heterogeneity of group $A$ agents can be accounted for by allowing $\alpha_{i}^{A}=l^{A}+\sigma^{A} v_{i}$ and/or $\lambda_{i}^{A}=m^{A}+\tau^{A} \varpi_{i}$ where $v$ and $\varpi$ are i.i.d. standard normal.

\section{Simulations}

In this section I use simulations to compare the two-sided market demand models with a one-sided logit demand model. For each model I generate 100 independent markets, each with five platforms (firms). Given platform characteristics and costs, I find the price and market share variables using profit maximization conditions.

\footnotetext{
${ }^{11}$ In some theoretical models, such as Rochet and Tirole (2003), platform-specific random coefficients $\left(\alpha_{i j}^{A}\right.$ instead of $\left.\alpha_{i}^{A}\right)$ play an important role in determining pricing structures. However, they are not estimable with the platform-level data I consider in this paper.
} 
In the one-sided logit model I define consumers' utility function as

$$
u_{i j t}=\mu_{j t}-\lambda p_{j t}+\xi_{j t}+\varepsilon_{i j t}
$$

where $\mu_{j t}$ is firm $j^{\prime} s$ mean quality, $p_{j t}$ its price, $\xi_{j t}$ firm-specific unobserved quality, and $\varepsilon_{i j t}$ an idiosyncratic error term with the type I extreme value distribution. Firm $j^{\prime} s$ profit function is given as

$$
\pi_{j t}=\left(p_{j t}-m c_{j t}\right) s_{j t}
$$

where $m c_{j t}$ is firm $j^{\prime} s$ marginal cost in market $t$ and $s_{j t}$ its market share.

Assuming

$$
\begin{aligned}
\mu_{j t} & \sim U(0,2) \\
\xi_{j t} & \sim 0.1 \times N(0,1) \\
m c_{j t} & \sim U(0,1) \\
\lambda & =2
\end{aligned}
$$

and firms compete á la Bertrand, I generate the profit maximizing prices and market shares for 100 independent markets.

In the single-homing model, the utility functions are

$$
\begin{aligned}
& u_{i j t}^{A}=\mu_{j t}^{A}-\lambda^{A} p_{j t}^{A}+\alpha^{A} s_{j t}^{B}+\xi_{j t}^{A}+\varepsilon_{i j t}^{A} \\
& u_{i j t}^{A}=\mu_{j t}^{B}-\lambda^{B} p_{j t}^{B}+\alpha^{B} s_{j t}^{A}+\xi_{j t}^{B}+\varepsilon_{i j t}^{B}
\end{aligned}
$$

and the profit function for platform $j$ is

$$
\pi_{j t}=\left(p_{j t}^{A}-m c_{j t}^{A}\right) s_{j t}^{A} M_{A}+\left(p_{j t}^{B}-m c_{j t}^{B}\right) s_{j t}^{B} M_{B}
$$


For the group A side, i.e., $\left(\mu_{j t}^{A}, \xi_{j t}^{A}, m c_{j t}^{A}, \lambda^{A}\right)$, I use the same values as $\left(\mu_{j t}, \xi_{j t}, m c_{j t}, \lambda\right)$ in the logit model. For the B side, I independently draw $\left(\mu_{j t}^{B}, \xi_{j t}^{B}, m c_{j t}^{B}\right)$ from the same distributions as those of $\left(\mu_{j t}^{A}, \xi_{j t}^{A}, m c_{j t}^{A}\right)$ and set $\lambda^{B}=2$ and $M_{A} / M_{B}=1$.I set $\left(\alpha^{A}, \alpha^{B}\right)=(1,1)$ so that each set of group agents likes the presence of the other group agents on a platform. I sort $\left(\mu_{j t}^{A}, \mu_{j t}^{B}, m c_{j t}^{A}, m c_{j t}^{B}\right)$ such that platform 1 has the lowest and platform 5 has the highest mean quality and marginal cost for both groups. In searching for prices and market shares that maximize the sum of profits from the two sides, I use the marginal cost as a starting point. ${ }^{12}$

In the competitive bottleneck model I use the same values as $\left(\mu_{j t}^{A}, \xi_{j t}^{A}, m c_{j t}^{A}, \lambda^{A}, \alpha^{A}\right)$ in the single-homing model for group A. The demand of group B agents is given as

$$
s_{j}^{B}=\frac{n_{j}^{B}}{M_{B}}=\left(1-G\left(\frac{p_{j}^{B}}{\omega_{j}\left(s_{j}^{A} M_{A}\right)} \mid \theta\right)\right)
$$

where $G\left(\alpha^{B}\right)$ is the cdf of the $\log$ normal distribution with $E\left(\log \left(\alpha^{B}\right)\right)=1$ and $\operatorname{Var}\left(\log \left(\alpha^{B}\right)\right)=$ 1 , and

$$
\omega_{j t}=\mu_{j t}^{B}+\xi_{j t}^{B}
$$

I set $M_{A} / M_{B}=10$ because it is more realistic to assume that the size of single-homing agents is much larger than the size of multi-homing agents. ${ }^{13}$

Table 1 shows the equilibrium prices and market shares averaged across 100 markets. Prices are lower and market shares are higher in the single-homing model than in the one-sided logit model. Platforms exploit the cross-group externalities by setting lower prices for both groups and attracting more agents from both sides. Not surprisingly, high quality platforms charge higher prices.

In the competitive bottleneck model, platforms charge much lower prices for group A agents than in the one-sided model, while charging much higher prices for group B agents. Some platforms even charge negative prices to group A. This is consistent with the common supposition

\footnotetext{
${ }^{12}$ I tried different starting points but obtained the same outcomes.

${ }^{13}$ Simulations show that when the two groups are of the equal size, some platforms are not attractive to any group $\mathrm{B}$ agents.
} 
that platforms make profits from multi-homing agents who join platforms as long as the benefit is larger than the price they pay. To charge high prices for group B agents, platforms try to attract as many group A agents as possible with low prices. Despite high prices, more than 30 percent of group B agents join platforms. Notice that unlike the single-homing model, higher quality platforms charge lower prices to group A agents.

In table 2 I increase the size of group $\mathrm{A}$ in both models. In the single-homing model the size of group A is 10 times larger than that of group B, and in the competitive bottleneck model it is 20 times larger. The two models react to this change in the opposite ways. In the former model, platforms increase prices for group A while decreasing prices for group B. Because group B agents are relatively scarcer, they become more valuable to platforms and are treated more favorably. Prices to group B agents go down so much that some of them are set below costs. In the latter model, platforms decrease prices for group A while increasing prices for multi-homing group B whose willingness to pay for joining them goes up. Despite higher prices, more group B agents join platforms.

In table 3 I compare the own-price elasticity computed using equation (10) (columns under Total) with its approximation using equation (11) (columns under Direct). The market size is set to $M_{A} / M_{B}=10$ for both models. The table shows that the approximation is much worse in the competitive bottleneck model with the magnitude of differences ranging from 31 to 63 percent for group A and 22 to 45 percent for group B, while it is less than 3 percent in the single-homing model. The table also shows that platforms do not necessarily set prices at the elastic part of the demand curve. In the single-homing model all platforms except platform 5 set prices at the inelastic part for group B. If markets are not two-sided, this cannot be a profit-maximizing pricing strategy. 


\section{Empirical Application: Magazine Advertising}

\subsection{Data}

I use data on magazines published in Germany to estimate the model presented in the previous sections. Magazines are platforms that serve readers on one side and advertisers on the other side. Advertisers care about the size of the reader base and readers may or may not like advertising.

I focus on TV magazines, which are categorized by Germany's Information Association for the Determination of the Spread of Advertising Media, a non-profit public institution equivalent to the US Audit Bureau of Circulation. Through its website, this association makes available quarterly information on copy prices, advertising prices, advertising pages, content pages, and circulations. Magazines are published at different frequencies. About $65 \%$ of TV magazines are published weekly, $28 \%$ bi-weekly and the remaining $7 \%$ monthly. The data aggregate the number of content and advertising pages and the circulation of each issue at a quarterly level, while recording the average per-issue copy and advertising prices.

Table 4 reports the summary statistics at a yearly level. The table shows a market-share weighted average (first averaging across magazines in each quarter and then averaging across quarters for each year) and a standard deviation for each variable. For the number of magazines, I report the number in the first quarter of each year. The advertising price is an average price that an advertiser pays for one page of advertising in one issue. Magazines charge slightly different prices depending on whether advertising is in color or not, but I use the average of the two. The table shows that the copy price and the advertising price are drastically different. Each copy is sold at around one euro, while one page of advertising is sold at around thirty thousand euros.

I treat all magazines as if they were selling a bundle of issues in each quarter. For example, I assume monthly magazines are selling a bundle of three issues and bi-weekly magazines are selling

a bundle of seven issues, and so on. This assumption implies that consumers decide which magazine to read each quarter and buy all issues in a given quarter. To be consistent with this assumption, 
I multiply the copy price by the number of issues and divide quarterly circulations by the number of issues in calculating market shares. For example, if the data show a monthly magazine sold 1.5 million copies in a quarter, my assumption implies that 500,000 consumers bought three issues of this magazine and paid its copy price three times in that quarter.

I make the same assumption for advertisers. If an advertiser chooses to advertise in a monthly magazine in a given quarter, he buys one advertising page in each issue and pays a perpage advertising price three times that quarter. This means that the number of advertisers is the number of advertising pages divided by the frequency. Putting the two sides together, 300 pages of advertising in a given quarter by a monthly magazine means 300 pages of advertising to consumers and 100 advertisers to a magazine. ${ }^{14}$

Magazines, on average, sell about 1.5 million copies, and have about 1,000 content pages and 250 advertising pages in each quarter. Large standard deviations imply that magazines are heterogeneous in terms of size and circulation. The average revenue from selling copies is about 1.5 million euros, while its advertising revenue is 7.5 million euros. It is hard to argue that the copy price covers the publishing cost. However, the low copy price is not unreasonable in the light of the two-sided market. The magazine may charge below marginal cost to sell as many copies as possible while charging a high price to advertisers to make profit.

During the sample period seven publishers published 19 magazines in total, seven of which remained in the market for the entire sample period. Table 4 shows that the number of magazines increased from 10 to 17 by 2005 and dropped to 15 in 2006 and stayed at that level until the end of the sample period. However, the market became much more concentrated in the late 2000s. In 1992 six publishers published ten magazines, adding five more magazines by 2000. Then, Gong Verlag GmbH \& Co. KG (GVG), which had been publishing a weekly magazine DieZwei and a biweekly magazine TVdirekt, sold its magazines to WAZ Verlagsgruppe (WAZ). In 2002 Michael Hahn Ver-

\footnotetext{
${ }^{14}$ An alternative approach is to assume that consumers and advertisers make decisions for each issue. Under this assumption I should make slight modifications in calculating market shares as well as the number of content and advertising pages consumers "consume". However, it does not significantly change empirical results.
} 
lag (MHV) entered the market with a monthly magazine nurTV and soon exited the market in 2005, selling its magazine to WAZ. In 2004 Hubert Burda Media (HBM) took over Verlagsgruppe Milchstrasse's (VM) two magazines. Thus, from 2006 only four publishers, Axel Springer Verlagsgruppe (ASV), Bauer Media KG (BMK), HBM and WAZ, remained in the market. ${ }^{15}$ These publishers publish a mixture of different frequency magazines. For example, WAZ publishes two weekly magazines, one bi-weekly magazine and one monthly.

These publishers also publish magazines in other magazine segments such as women, business and politics, adult, automotive, etc. An exception is WAZ, which only publishes women's magazines and pet magazines other than TV magazines. I exploit this multi-segment feature in constructing instrumental variables. For example, the prices of magazines in different segments that are published by the same publisher can be used as IVs for the price variable, because they are likely to be correlated through common publisher cost factors but demand shocks are unlikely to be correlated across segments.

\subsection{Demand Estimation: Competitive Bottleneck}

I assume that consumers choose at most one TV magazine title per quarter and consumer $i^{\prime} s$ indirect utility of purchasing magazine $j$ in period $t$ is

$$
u_{i j t}^{A}=\mathbf{x}_{j t} \boldsymbol{\beta}-\lambda p_{j t}^{A}+\xi_{j t}+\varepsilon_{i j t}
$$

where $\mathbf{x}_{j t}$ is a vector of observed magazine attributes, $p_{j t}^{A}$ magazine copy price, $\xi_{j t}$ unobservable attribute and demand shock and $\varepsilon_{i j t}$ an idiosyncratic taste shock with type I extreme value distribution. $\mathbf{x}$ includes the magazine fixed effect, the time effect, the number of content pages and the number of advertising pages. Both the copy price and the advertising pages are endogenous variables that are correlated with the unobservable attribute.

\footnotetext{
${ }^{15}$ Two magazines published by Hubert Burda Media are excluded from the sample from 2006 because their attribute data are missing. This explains a drop in the number of magazines from 17 to 15 in 2006 in table 4 .
} 
An advertiser, whose type is $\alpha_{i}^{B}$, buys an advertising page if its net profit is positive. The advertising profit is defined as

$$
\pi_{i j t}^{B}=\alpha_{i}^{B} \omega_{j t} n_{j t}^{A}-p_{j t}^{B}
$$

where $p_{j t}^{B}$ is price magazine $j$ charges to an advertiser, $n_{j t}^{A}$ the number of readers for magazine $j$, and $\omega_{j t}$ a per-reader profitability of one page advertising. I assume that its advertising decision regarding one magazine is independent of its decision regarding another. ${ }^{16}$ Thus, there is no direct competition between magazines to attract advertisers and each magazine acts as a monopolist towards advertisers. However, there is still an indirect competition between magazines as long as readers care about (like or dislike) advertising. Given the distribution of advertiser type, $F(\alpha \mid \theta)$, the number of advertising pages in magazine $j, n_{j}^{B}$, is determined by

$$
n_{j t}^{B}=\left(1-F\left(\frac{p_{j t}^{B}}{\omega_{j t} n_{j t}^{A}} \mid \boldsymbol{\theta}\right)\right) M_{B}
$$

where $M_{B}$ the number of advertisers in the market and $F(\boldsymbol{\theta})$ is assumed to be the lognormal distribution with the mean parameter 0 and the variance parameter 1.4. Notice that the distribution parameters are not estimable and should be fixed as part of normalization. ${ }^{17}$ Thus, estimating advertisers' demand is equivalent to imputing the mean benefit (profitability) that advertisers receive from advertising in magazines, i.e., $\boldsymbol{\omega}$, and projecting it on characteristics space. I discuss how this normalization affects demand estimates below.

I use the generalized method of moment to simultaneously estimate the following system of demand equations

$$
\begin{aligned}
\log \left(s_{j t}\right)-\log \left(s_{0 t}\right) & =\mathbf{x}_{j t} \boldsymbol{\beta}-\lambda p_{j t}^{A}+\xi_{j t} \\
\log \left(\omega_{j t}\right) & =\mathbf{w}_{j t} \boldsymbol{\gamma}+e_{j t}
\end{aligned}
$$

\footnotetext{
${ }^{16}$ In my opinion the competitive bottleneck model describes advertisers better than the two-sided single-homing model. The latter model assumes that advertisers select only one magazine for advertising. Nevertheless, I still estimate this model in the appendix for the sake of comparison.

${ }^{17}$ I explain why I choose these values in the next section.
} 
where $\mathbf{w}$ includes the magazine fixed effect, the time effect and the number of content pages. Moment conditions are that the demand residuals in the two equations, $\left(\xi_{j t}, e_{j t}\right)$, are not correlated with the number of content pages, the time effects, and the mean magazine quality for readers and advertisers, i.e. the magazine fixed effects. In addition, I use the same and rival publishers' average copy price and advertising pages in other magazine segments such as women's magazines, automotive magazines, etc. as instrumental variables. An identifying assumption is that copy prices and advertising pages are correlated across magazine segments because of common cost shocks but demand shocks are not correlated across magazine segments.

Table 5 shows estimation results, and in the appendix I estimate the model using alternative specifications for the advertiser profit function. The number of potential readers is set to 40 million and the number of potential advertisers is set to 200. Both numbers are set to exceed per-period maximum copy sales and advertising pages respectively. Notice that advertising pages reported in table 4 are the aggregated number for each quarter and a frequency-adjusted advertising page is no larger than 150 pages. The magazine fixed effects and the time effects are included in all estimations but not reported.

The first column shows OLS results for equations (18) and (19) respectively. In equation (18) the price coefficient is negative but statistically insignificant. Both the advertising page and the content page coefficients are positive and significant at the 5 percent level. In equation (19) the content page coefficient is negative and significant. The R-square is 0.96 for the former equation and 0.91 for the latter.

The second column shows the system IV results. I use $\left(\mathbf{Z}^{\prime} \mathbf{Z}\right)^{-1}$ as a weighting matrix where $\mathbf{Z}$ is an IV matrix. In the first equation both the price coefficient and the advertising page coefficient change significantly. The former goes down from -0.017 to -0.135 and becomes significant and the latter goes up from 0.116 to 0.208 . The positive advertising page coefficient implies that readers like advertising in TV magazines. The fact that the advertising coefficient goes up with IVs does not necessarily mean that the advertising page variable is negatively correlated with the demand 
residual. When there are two endogenous variables, it is hard to predict the sign of inconsistency in the OLS estimates because it is driven by how strongly the two endogenous variables are correlated with the error term. I test if the instruments used for the first equation are weak IVs with the first stage F-test. The F-statistics are 24.43 for the price variable and 24.84 for the advertising page variable.

The last column shows the GMM results, using the inverse of the variance of the moment conditions as the weighting matrix. The weighting matrix is optimal such that standard errors are smallest under the current moment conditions. The price coefficient goes down little further to -0.155 but the advertising page coefficient hardly changes. The content page coefficient does not change across the columns. I test the overidentifying restrictions and accept them with the test statistics close to zero.

The magazine fixed effects show that popular magazines do not necessarily have higher per-reader profitability for advertisers. A correlation between a quality ranking for readers and a quality ranking for advertisers is -0.45 using the system IV estimates and -0.29 using the GMM estimates. For example, the "lowest profitable" magazine for advertisers, i.e., BMK's tvpur, in both estimations is estimated to be the fourth or fifth highest quality for readers. This suggests that magazine quality not captured by the size of reader basis is also important in explaining advertising price differences across magazines.

Different parameter values of the advertiser distribution (i.e., $F(\boldsymbol{\theta}))$ mainly affects the constant term of the advertising demand equation. When the variance parameter varies from 0.5 to 3 with the mean parameter fixed, the constant term decreases from 1.702 to -0.628 , but the other estimates hardly change. For example, the content page coefficient changes from -0.103 to -0.115. Different market sizes have similar effects. As the number of potential advertisers increases from 150 to 500, the constant term decreases from 1.126 to 0.175 while the other estimates hardly change. However, their impact on markup is more substantial, and I discuss it in more detail below. 


\subsection{Elasticity and Market Power}

Table 6 summarizes price elasticities calculated from the demand estimates. The left panel shows the own-price elasticities in the one-sided model $\left(\frac{\partial S_{j}^{A}}{\partial p_{j}^{A}} \frac{p_{j}^{A}}{s_{j}^{A}}\right.$ and $\left.\frac{\partial S_{j}^{B}}{\partial p_{j}^{B}} \frac{p_{j}^{B}}{s_{j}^{B}}\right)$ which do not account for the feedback loop following a price change. The right panel shows the price elasticities in the twosided model including the own-price elasticities for readers $\left(\frac{\partial s_{j}^{A}}{\partial p_{j}^{A}} \frac{p_{j}^{A}}{s_{j}^{A}}\right)$ and advertisers $\left(\frac{\partial s_{j}^{B}}{\partial p_{j}^{B}} \frac{p_{j}^{B}}{s_{j}^{B}}\right)$ and the cross-group price elasticities $\left(\frac{\partial s_{j}^{A}}{\partial p_{j}^{B}} \frac{p_{j}^{B}}{s_{j}^{A}}\right.$ and $\left.\frac{\partial s_{j}^{B}}{\partial p_{j}^{A}} \frac{p_{j}^{A}}{s_{j}^{B}}\right)$. The latter measures a percent change in the number of readers (advertisers) with respect to one percent change in the advertising (copy) price. Compared to the one-sided model, the own-price elasticities go up (in the absolute term) by about 4 percent.

The cross-group elasticities show that advertisers are much more sensitive to a price change on the other side. The median cross-group elasticity with respect to a copy price $\left(\frac{\partial s_{j}^{B}}{\partial p_{j}^{A}} \frac{p_{j}^{A}}{s_{j}^{B}}\right)$ is -2.58 while it is -0.04 with respect to an advertising price $\left(\frac{\partial s_{j}^{A}}{\partial p_{j}^{B}} \frac{p_{j}^{B}}{s_{j}^{A}}\right)$. This implies that given the size of the two groups, the markup on the reader side is much more heavily adjusted than the markup on the advertiser side. To see this, plug the median elasticities into equations (14) and (15).

$$
\begin{aligned}
& \left(p_{j}^{A}-c_{j}^{A}\right)=0.59 p_{j}^{A}-1.53\left(p_{j}^{B}-c_{j}^{B}\right) \frac{n_{j}^{B}}{n_{j}^{A}} \\
& \left(p_{j}^{B}-c_{j}^{B}\right)=0.70 p_{j}^{B}-0.03\left(p_{j}^{A}-c_{j}^{A}\right) \frac{n_{j}^{A}}{n_{j}^{B}}
\end{aligned}
$$

These equations show that, given the group size, the markup on the reader side is adjusted by 1.53 times of the markup on the advertiser side, while the markup on the advertiser side is adjusted by a small fraction (0.03) of the markup on the other side. Of course, the group size, which is substantially different, is another determinant of the markup.

Whether readers like or dislike advertising changes the sign of the cross-group elasticity and advertisers' cross-price elasticity among platforms. If readers dislike advertising, $\partial s_{j}^{A} / \partial p_{j}^{B}$ becomes positive and $\partial s_{j}^{B} / \partial p_{k}^{B}, j \neq k$ become negative. If readers are indifferent about advertising, both 
$\partial s_{j}^{A} / \partial p_{j}^{B}$ and $\partial s_{j}^{B} / \partial p_{k}^{B}, j \neq k$ become zero. As mentioned above, although pricing for advertisers is modeled as monopolistic, the cross-group interaction makes advertisers' cross-price elasticity (among platforms) non-zero, i.e. $\left(\partial s_{j}^{B} / \partial p_{k}^{B}\right)\left(p_{k}^{B} / s_{j}^{B}\right) \neq 0, j \neq k$. However, its magnitude is so small (the mean cross elasticity is less than 0.001) that its impact on advertising pricing and markups are negligible.

Table 7 reports per-issue marginal costs and markups. I report per-issue estimates to make them comparable with prices reported in table 4. On the left panel I report marginal costs and markups in the one-sided model where platforms maximize profits on each side separately. The reader-side estimates imply the median marginal cost for producing an over 100-page magazine is 0.40 euros and it costs less than 0.60 euros to produce a 200-page magazine (the $5^{\text {th }}$ quintile magazine). The median markup is 62 percent with close to 80 percent of magazines having higher than a 50 percent markup. The median markup in the one-sided advertising market is 73 percent with the mean markup equal to 84 percent.

On the right panel I report marginal costs and markups that account for the two-sidedness. Very different markup structures are seen on the reader side when the advertising side is accounted for. Although demand estimates do not change significantly, publishers' profit-maximizing behaviors are drastically different. The median cost is now 3.39 euros, which results in a negative markup (-2.39 euros). In fact, 90 percent of magazines are estimated to incur a loss from selling their magazines. However, this loss is fully recovered from selling advertising space. Magazines, on average, earn about 20,000 euros from selling one advertising page. The average percentage markup is 83 percent, slightly lower than the one-sided model estimate. Combining the two sides, magazines, on average, make about 65,000 euros per issue with 445,000 euro loss from selling magazines and 510,000 euro profit from selling advertising space.

However, magazines do not always incur a loss from selling their copies. Six magazines made profits on the readers' side in at least one quarter during the sample period. Four of these magazines are published by BMK, which owns the highest number of magazines. This suggests 
that a publisher can still set magazine prices above costs when it has substantial market power. Nevertheless, this is not a common phenomenon. It only happens to 11 percent of all observations, and in any period no more than two magazines make profits from selling copies.

The estimated profits show that the advertising profit is almost perfectly negatively correlated with the copy-sale profit. For six publishers, a correlation between these two profits is lower than -0.90 . This means that an increase in the advertising profit almost always accompanies a decrease in the copy-sale profit. This is consistent with the simulation in section 4 that shows that a platform with a higher advertising profit incurs a larger loss on the reader side.

Notice that even if readers dislike advertising, the markup results do not change in a fundamental way. In particular, negative advertising preference makes the advertising markup higher because magazines want to charge more to advertisers to compensate readers' disutility, which makes estimated marginal costs lower for the same observed prices. This implies that the markup structure is mainly determined by magazines who act as "monopolists" towards advertisers and advertisers who are willing to pay a lot of money to interact with readers.

While the market size and the parameter (variance) values of the advertiser distribution mainly affect the constant term in the demand estimation, their impact on markups is more substantial and how I set their values deserves more explanation. I use 40 million, about a half of the German population, as the market size for readers to include all potential readers of TV magazines in Germany. The market size for advertisers is less straightforward to set, but my assumption about how advertisers make decisions restricts the number of advertisers to be no less than the maximum advertising pages per issue which is 147. My choice of 200 advertisers, therefore, means that 53 potential advertisers never advertised in any TV magazines during the sample period. A lower number increases markup but not substantially.

A reasonable range for the variance of the advertiser distribution, given the market sizes set above, is between 1 and 1.7. When it is 1 , the markup on the advertising side is so low that five out of seven publishers make negative profits over the entire sample period. When it is 1.7, all 
publishers make positive profits but the average markup is close to one. My choice of 1.4 is the lowest value that makes all publishers earn positive profits over the entire sample period.

\subsection{Merger Simulations}

In this section I analyze how equilibrium prices and market shares (the number of participations) change when the market becomes more concentrated. In particular, I focus on the shift from the single magazine ownership to the monopoly (one publisher owning all magazines). Since this change is from one extreme to the other, it is supposed to result in the most drastic change among any other possible ownership changes. As the benchmark case I do the same exercise for the one-sided logit model. The comparison will shed light on how mergers in the two-sided market differ from the one-sided market.

The observed markets are oligopolistic with three publishers owning two-thirds of TV magazines. I use the magazine-level markup and cost reported in the previous section for the current market structure. For the two hypothetical market structures I plug these cost estimates into the markup equations (equations (14) and (15)) to find new equilibrium prices and market shares. The search algorithm consists of two parts. While an outer part searches for prices that satisfy the markup equations with a different ownership structure, an inner part searches for market shares that satisfy equations (8) and (9) simultaneously for given prices. ${ }^{18}$

Results show that copy prices can either increase or decrease in the two-sided market, while they always increase in the one-sided market. Advertising prices can also either increase or decrease but always move in the opposite direction from copy prices. Given a market (a quarter) the merged publisher decreases copy prices (and increases advertising prices) for about two-thirds of magazines.

Table 8 shows price changes for the third quarter of 2004 as an example. I report results on 10 magazines out of 17 in that quarter. The left panel shows changes in copy prices in the

\footnotetext{
${ }^{18}$ As mentioned above, Brouwer's fixed point theorem guarantees the existence of these shares. Although there can be multiple sets of shares that satisfy the demand equations, it does not seem to occur in my exercise.
} 
one-sided market model. The price increase is from as small as 3 cents to as large as 12 cents. The right panel of the table shows changes in copy prices and advertising prices in the two-sided market setting. The magnitude of copy price changes is similar to the one-sided market but they move in either direction. The magnitude of advertising price changes is much bigger, although it is smaller in the percentage term.

Market shares change as a response not only to price changes but also to market share changes on the other side. For this reason higher prices do not necessarily result in smaller market shares. Table 9 shows market share changes for the same magazines in the same period as table 8 . It shows that lower copy prices result in higher magazine sales, but more advertisers join platforms despite higher advertising prices. This implies that on the advertiser side the demand shifts out so much that its effects dominate price effects.

These results suggest that mergers could be much less harmful for readers than what the one-sided market model predicts and that consumers may even benefit from them. For the third quarter of 2004 the one-sided model predicts that readers' welfare goes down by 5 percent while the two-sided model predicts a 0.14 percent welfare decrease. Whether consumers benefit from mergers depends on the magnitudes of copy price and advertising changes, although the latter effect is relatively marginal. A closer look shows that readers' welfare would not go down in the third quarter of 2004 if it were not for Magazine 10's price increase of over 10 percent. Simulations show that in the symmetric equilibrium the merged publisher decreases all magazines' copy prices and, as a result, readers' welfare goes up. ${ }^{19}$

As is the case with readers, mergers may or may not harm advertisers. The results above show that two-thirds of magazines lower copy prices and raise advertising prices in shifting from the single magazine ownership to the monopoly. Higher advertising prices hurt advertisers, but more readers, attracted by lower copy prices, benefit advertisers. To measure net effects, I first calculate

\footnotetext{
${ }^{19}$ Consumer welfare may not change monotonically as the market becomes more concentrated. For example, in the third quarter of 2004 consumer welfare increases when the market changes from the single to the current oligopolistic ownership structure but then decreases when the market moves towards the monopoly structure. This happens as some magazines sharply increase their copy prices in a monopoly market.
} 
the surplus of the average advertiser on magazine $j$ by

$$
E\left(\alpha_{i}^{B} \mid i \in j\right) \omega_{j} n_{j}^{A}-p_{j}^{B}
$$

where $E\left(\alpha_{i}^{B} \mid i \in j\right)$ denotes the average value of $\alpha_{i}^{B}$ conditional on joining magazine $j$. Then I multiply the average surplus by the number of advertisers joining each magazine.

Results show that the average surplus goes up on magazines that raise advertising prices. Since these magazines attract more advertisers, advertisers' total surplus also goes up. For the third quarter of 2004, the increase is 30 percent at Magazine 7 and 15 percent at Magazine 1. On the other hand, advertisers' surplus goes down on magazines that lower advertising prices, but fewer magazines do so and changes are less than 10 percent. For the whole market, as a result, advertisers' aggregate surplus increases by 1.7 percent. $^{20}$

\section{Conclusions}

In this paper I develop structural models of two-sided markets where two groups of agents interact through oligopolistic platforms and estimate platform markups using TV magazine data in Germany. My models have two key features of the two-sided market. First, both groups care about the presence of the other group, so the cross-group externalities are present on both sides. Second, platforms set different prices for each group to maximize joint profits from both sides. To account for these cross-group externalities I treat market share equations as a system of implicit functions where platform prices are control variables and the market share of both sides are endogenous variables. I use the implicit function theorem to compute the price elasticities and recover platform markups.

The empirical results show that most of the magazines set copy prices below marginal costs to attract readers and make profits from selling advertising space. When the advertising

\footnotetext{
${ }^{20} \mathrm{An}$ important assumption in this exercise is that the merged publisher keeps all magazines and do not change their other characteristics. Rysman (2004) shows that advertisers are better off with more platforms.
} 
side is ignored, the same demand estimates imply high markups on the reader side. Counterfactual exercises show that platform mergers do not necessarily increase copy prices and, as a result, readers may not necessarily be worse off in more concentrated markets.

Some extensions are worth consideration. First, I assume there is no intra-platform competition but it can be an important factor in agents' membership decisions. For example, advertisers' platform valuation may go down with the number of other advertisers on the same platform. This is equivalent to congestion, or negative externalities, in network industries. With intra-platform competition a few interesting issues arise including whether platforms would choose exclusive dealing and how prices on the other side are affected. Second, I only consider the fixed membership fee in this paper but incorporating more flexible fee structures, such as charging usage fees, are certainly important topics for future empirical research. 


\section{References}

[1] Argentesi, E. and L. Filistrucchi (2007), "Estimating Market Power in a Two-sided Market: The Case of Newspapers," Journal of Applied Econometrics, 22, 1247-1266.

[2] Armstrong, M. (2006), "Competition in Two-sided Markets," RAND Journal of Economics, 37, 668-691.

[3] Berry, S. (1994), "Estimating Discrete Choice Models of Product Differentiation," RAND Journal of Economics, 25, 242-262.

[4] Berry, S., J. Levinsohn, and A. Pakes (1995), "Automobile Prices in Market Equilibrium," Econometrica, 63, 841-890.

[5] Chandra, A. and A. Collard-Wexler (forthcoming), "Mergers in Two-Sided Markets: An Application to the Canadian Newspaper Industry," Journal of Economics and Management Strategy.

[6] Jeziorski, P. (2011), "Merger Enforcement in Two-sided Markets," unpublished manuscript, Johns Hopkins University.

[7] Jin, G. and M. Rysman (2010), "Platform Pricing at Sports Card Conventions," unpublished manuscript, Boston University.

[8] Kaiser, U. and J. Wright (2006), "Price Structure in Two-Sided Markets: Evidence from the Magazine Industry," International Journal of Industrial Organization, 24, 1-28.

[9] Rochet, J.-C. and Tirole, J. (2003), "Platform Competition in Two-Sided Markets," Journal of the European Economic Association, 1, 990-1029.

[10] Rochet, J.-C. and Tirole, J. (2006), "Two-Sided Markets: A Progress Report," RAND Journal of Economics, 37, 645-667.

[11] Rosen, J. (1965), "Existence and Uniqueness of Equilibrium Points for Concave n-person Games," Econometrica, 33, 520-534.

[12] Rysman, M. (2004), "Competition between Networks: A Study of the Market for Yellow Pages," Review of Economic Studies, 71, 483-512.

[13] Rysman, M. (2009), "The Economics of Two-Sided Markets," Journal of Economic Perspective, $23,125-143$.

[14] Weyl, G. and A. White (2010), "Imperfect Platform Competition: A General Framework," unpublished manuscript, Harvard University. 
Table 1: Average Price and Market Share in Equilibrium

\begin{tabular}{|c|c|c|c|c|c|c|c|c|c|c|}
\hline \multirow[b]{3}{*}{ Platform } & \multirow{2}{*}{\multicolumn{2}{|c|}{$\frac{\text { Logit Model }}{\text { Group A }}$}} & \multicolumn{4}{|c|}{ Single-Homing } & \multicolumn{4}{|c|}{ Competitive Bottleneck } \\
\hline & & & \multicolumn{2}{|c|}{ Group A } & \multicolumn{2}{|c|}{ Group B } & \multicolumn{2}{|c|}{ Group A } & \multicolumn{2}{|c|}{ Group B } \\
\hline & Price & Share & Price & Share & Price & Share & Price & Share & Price & Share \\
\hline 1 & 0.748 & 0.126 & 0.679 & 0.136 & 0.664 & 0.131 & 0.263 & 0.032 & 0.574 & 0.300 \\
\hline 2 & 0.932 & 0.124 & 0.852 & 0.131 & 0.815 & 0.133 & 0.118 & 0.061 & 1.820 & 0.282 \\
\hline 3 & 1.089 & 0.122 & 1.028 & 0.130 & 0.989 & 0.138 & -0.262 & 0.137 & 5.453 & 0.365 \\
\hline 4 & 1.237 & 0.128 & 1.174 & 0.136 & 1.150 & 0.142 & -0.569 & 0.289 & 13.929 & 0.408 \\
\hline 5 & 1.418 & 0.117 & 1.335 & 0.137 & 1.336 & 0.135 & -0.649 & 0.458 & 26.303 & 0.409 \\
\hline
\end{tabular}

The market size is set to $\mathrm{M}_{A} / \mathrm{M}_{B}=1$ for the single-homing model and $\mathrm{M}_{A} / \mathrm{M}_{B}=10$ for the competitive bottleneck model. 
Table 2: Average Price and Market Share with Different Market Sizes

\begin{tabular}{|c|c|c|c|c|c|c|c|c|}
\hline \multirow[b]{3}{*}{ Platform } & \multicolumn{4}{|c|}{ Single-Homing } & \multicolumn{4}{|c|}{ Competitive Bottleneck } \\
\hline & \multicolumn{2}{|c|}{ Group A } & \multicolumn{2}{|c|}{ Group B } & \multicolumn{2}{|c|}{ Group A } & \multicolumn{2}{|c|}{ Group B } \\
\hline & Price & Share & Price & Share & Price & Share & Price & Share \\
\hline 1 & 0.740 & 0.133 & 0.016 & 0.177 & 0.255 & 0.035 & 0.891 & 0.450 \\
\hline 2 & 0.915 & 0.128 & 0.186 & 0.171 & 0.060 & 0.062 & 3.188 & 0.365 \\
\hline 3 & 1.092 & 0.126 & 0.363 & 0.172 & -0.317 & 0.139 & 10.547 & 0.416 \\
\hline 4 & 1.239 & 0.132 & 0.496 & 0.186 & -0.569 & 0.282 & 26.380 & 0.427 \\
\hline 5 & 1.398 & 0.134 & 0.679 & 0.183 & -0.653 & 0.460 & 51.699 & 0.421 \\
\hline
\end{tabular}

The market size is set to $\mathrm{M}_{A} / \mathrm{M}_{B}=10$ for the single-homing model and $\mathrm{M}_{A} / \mathrm{M}_{B}=20$ for the competitive bottleneck model. 
Table 3: Average Own-Price Elasticities

\begin{tabular}{|c|c|c|c|c|c|c|c|c|}
\hline \multirow[b]{3}{*}{ Platform } & \multicolumn{4}{|c|}{ Single-Homing } & \multicolumn{4}{|c|}{ Competitive Bottleneck } \\
\hline & \multicolumn{2}{|c|}{ Group A } & \multicolumn{2}{|c|}{ Group B } & \multicolumn{2}{|c|}{ Group A } & \multicolumn{2}{|c|}{ Group B } \\
\hline & Direct & Total & Direct & Total & Direct & Total & Direct & Total \\
\hline 1 & -1.283 & -1.312 & -0.292 & -0.299 & -0.850 & -1.115 & -1.585 & -1.930 \\
\hline 2 & -1.604 & -1.637 & -0.468 & -0.476 & -0.975 & -1.336 & -1.460 & -1.880 \\
\hline 3 & -1.913 & -1.954 & -0.683 & -0.695 & -0.965 & -1.494 & -1.107 & -1.589 \\
\hline 4 & -2.161 & -2.210 & -0.885 & -0.904 & -0.900 & -1.466 & -0.953 & -1.379 \\
\hline 5 & -2.427 & -2.483 & -1.168 & -1.192 & -0.774 & -1.255 & -0.949 & -1.273 \\
\hline
\end{tabular}

The market size is set to $M_{A} / M_{B}=10$ for both models. 


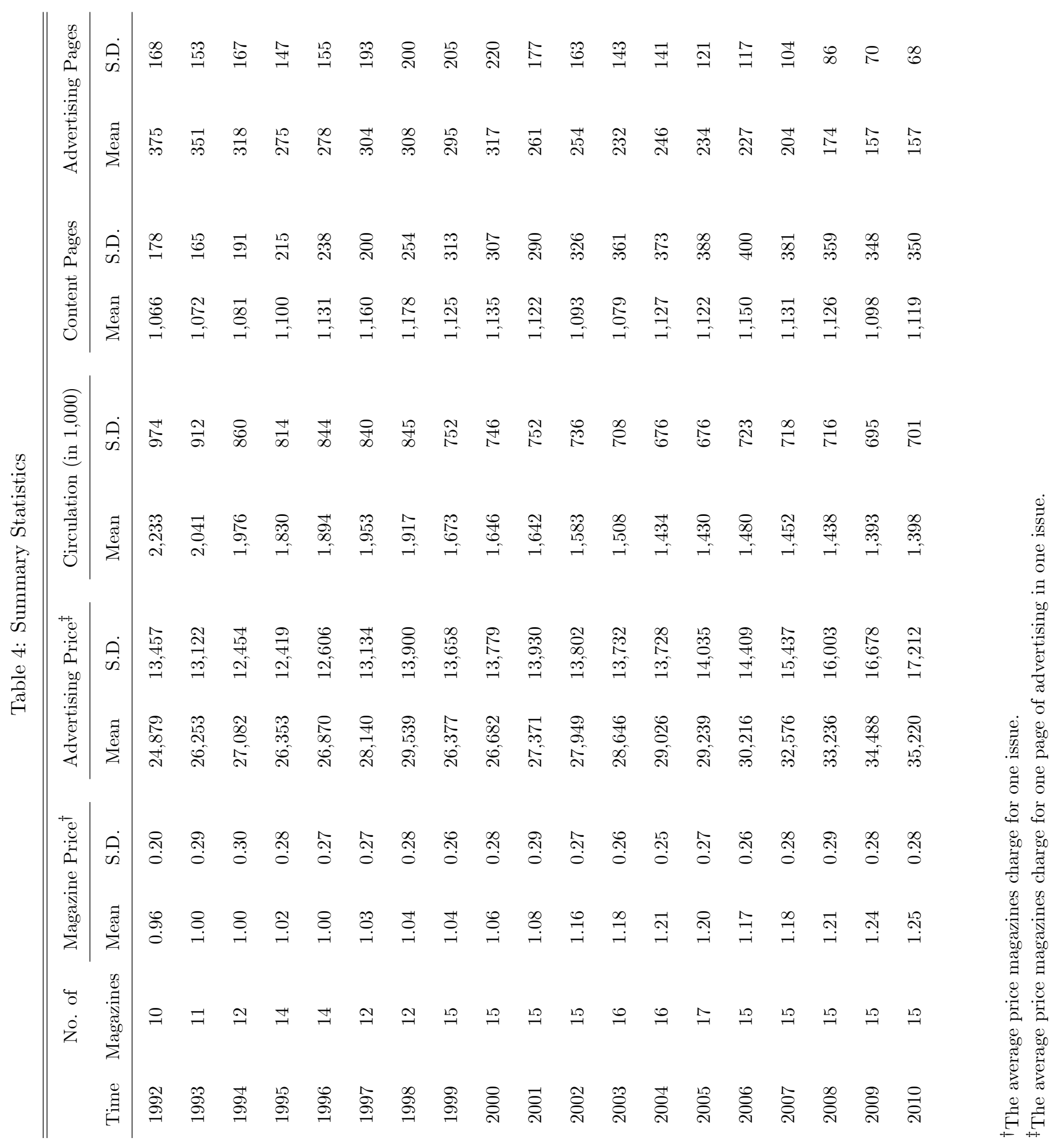


Table 5: Demand Estimation Results

\begin{tabular}{|c|c|c|c|c|}
\hline Variable & & OLS & System IV & GMM \\
\hline \multirow[t]{4}{*}{ Readers } & Constant & $\begin{array}{c}-7.250^{*} \\
(0.235)\end{array}$ & $\begin{array}{c}-5.604^{*} \\
(0.640)\end{array}$ & $\begin{array}{l}-5.111^{*} \\
(0.612)\end{array}$ \\
\hline & Copy Price & $\begin{array}{c}-0.017 \\
(0.012)\end{array}$ & $\begin{array}{l}-0.135^{*} \\
(0.033)\end{array}$ & $\begin{array}{l}-0.155^{*} \\
(0.032)\end{array}$ \\
\hline & Ads Page & $\begin{array}{c}0.116^{*} \\
(0.011)\end{array}$ & $\begin{array}{c}0.208^{*} \\
(0.030)\end{array}$ & $\begin{array}{l}0.204^{*} \\
(0.028)\end{array}$ \\
\hline & Content Page & $\begin{array}{c}0.062^{*} \\
(0.007)\end{array}$ & $\begin{array}{c}0.069^{*} \\
(0.008)\end{array}$ & $\begin{array}{l}0.060^{*} \\
(0.008)\end{array}$ \\
\hline \multirow[t]{2}{*}{ Advertisers } & Constant & $\begin{array}{c}0.727^{*} \\
(0.160)\end{array}$ & $\begin{array}{c}0.727^{*} \\
(0.242)\end{array}$ & $\begin{array}{l}0.900^{*} \\
(0.233)\end{array}$ \\
\hline & Content Page & $\begin{array}{c}-0.102^{*} \\
(0.010)\end{array}$ & $\begin{array}{c}-0.102^{*} \\
(0.012)\end{array}$ & $\begin{array}{c}-0.110^{*} \\
(0.011)\end{array}$ \\
\hline
\end{tabular}

The market size for readers is set to 40 million and the market size for advertisers to 200 . The magazine fixed effects and the time effects are included in all estimations.

Standard errors are reported in parenthesis.

*significant at the $5 \%$ level. 
Table 6: Price Elasticity

\begin{tabular}{|c|c|c|c|c|c|c|}
\hline & \multicolumn{2}{|c|}{ One-Sided } & \multicolumn{4}{|c|}{ Two-Sided } \\
\hline & $\frac{\partial S_{j}^{A}}{\partial p_{j}^{A}} \frac{p_{j}^{A}}{s_{j}^{A}}$ & $\frac{\partial S_{j}^{B}}{\partial p_{j}^{B}} \frac{p_{j}^{B}}{s_{j}^{B}}$ & $\frac{\partial s_{j}^{A}}{\partial p_{j}^{A}} \frac{p_{j}^{A}}{s_{j}^{A}}$ & $\frac{\partial s_{j}^{B}}{\partial p_{j}^{B}} \frac{p_{j}^{B}}{s_{j}^{B}}$ & $\frac{\partial s_{j}^{A}}{\partial p_{j}^{B}} \frac{p_{j}^{B}}{s_{j}^{A}}$ & $\frac{\partial s_{j}^{B}}{\partial p_{j}^{A}} \frac{p_{j}^{A}}{s_{j}^{B}}$ \\
\hline Median & -1.64 & -1.38 & -1.69 & -1.43 & -0.04 & -2.58 \\
\hline Mean & -1.68 & -1.31 & -1.77 & -1.37 & -0.05 & -2.32 \\
\hline $20 \% \mathrm{QU}^{*}$ & -1.21 & -1.02 & -1.30 & -1.11 & -0.02 & -1.04 \\
\hline $80 \% \mathrm{QU}$ & -2.12 & -1.60 & -2.17 & -1.63 & -0.08 & -3.28 \\
\hline
\end{tabular}

The market size for readers is set to 40 million and the market size for advertisers to 200 . $A$ refers to the reader side and $B$ refers to the advertiser side. ${ }^{*} \mathrm{QU}$ refers to a quintile. 
Table 7: Magazine Market Power

\begin{tabular}{|c|c|c|c|c|c|c|c|}
\hline \multirow[b]{2}{*}{ Markets } & & \multicolumn{3}{|c|}{ One-Sided } & \multicolumn{3}{|c|}{ Two-Sided } \\
\hline & & Cost & Markup & \% Markup & Cost & Markup & $\%$ Markup \\
\hline \multirow[t]{4}{*}{ Readers } & Median & 0.40 & 0.51 & 0.62 & 3.39 & -2.39 & -2.26 \\
\hline & Mean & 0.29 & 0.79 & 0.78 & 4.23 & -3.15 & -2.58 \\
\hline & $20 \% \mathrm{QU}^{*}$ & 0.13 & 0.50 & 0.48 & 1.56 & -5.48 & -4.52 \\
\hline & $80 \% \mathrm{QU}$ & 0.54 & 1.09 & 0.83 & 6.83 & -0.74 & -0.88 \\
\hline \multirow[t]{4}{*}{ Advertisers } & Median & 2,761 & 13,733 & 0.73 & 3,061 & 13,580 & 0.72 \\
\hline & Mean & 1,031 & 21,446 & 0.84 & 1,329 & 21,148 & 0.83 \\
\hline & $20 \% \mathrm{QU}$ & 599 & 5,469 & 0.63 & 950 & 5,283 & 0.61 \\
\hline & $80 \% \mathrm{QU}$ & 7,890 & 32,115 & 0.98 & 7,999 & 31,582 & 0.96 \\
\hline
\end{tabular}

The market size for readers is set to 40 million and the market size for advertisers to 200 . ${ }^{*} \mathrm{QU}$ refers to a quintile. 
Table 8: Price Changes from the Single Magazine Onwership to the Monopoly

\begin{tabular}{|c|c|c|c|c|c|}
\hline & & \multicolumn{2}{|c|}{ One-Sided } & \multicolumn{2}{|c|}{ Two-Sided } \\
\hline & & Single & Monopoly & Single & Monopoly \\
\hline \multicolumn{6}{|l|}{ Readers } \\
\hline & Magazine 1 & 1.42 & 1.45 & 1.43 & 1.38 \\
\hline & Magazine 2 & 0.99 & 1.04 & 0.99 & 1.05 \\
\hline & Magazine 3 & 1.00 & 1.03 & 1.03 & 1.00 \\
\hline & Magazine 4 & 0.70 & 0.72 & 0.73 & 0.70 \\
\hline & Magazine 5 & 1.42 & 1.47 & 1.42 & 1.48 \\
\hline & Magazine 6 & 1.41 & 1.47 & 1.41 & 1.49 \\
\hline & Magazine 7 & 1.41 & 1.43 & 1.44 & 1.41 \\
\hline & Magazine 8 & 1.00 & 1.03 & 1.05 & 0.98 \\
\hline & Magazine 9 & 1.01 & 1.07 & 1.01 & 1.09 \\
\hline & Magazine 10 & 1.27 & 1.38 & 1.27 & 1.41 \\
\hline \multicolumn{6}{|l|}{ Advertisers } \\
\hline & Magazine 1 & & & 37,643 & 39,128 \\
\hline & Magazine 2 & & & 28,427 & 27,216 \\
\hline & Magazine 3 & & & 19,940 & 20,306 \\
\hline & Magazine 4 & & & 21,629 & 21,933 \\
\hline & Magazine 5 & & & 17,329 & 16,469 \\
\hline & Magazine 6 & & & 19,110 & 18,160 \\
\hline & Magazine 7 & & & 28,395 & 29,177 \\
\hline & Magazine 8 & & & 28,267 & 29,618 \\
\hline & Magazine 9 & & & 13,202 & 12,644 \\
\hline & Magazine 10 & & & 12,488 & 12,154 \\
\hline
\end{tabular}


Table 9: Participation Changes from the Single Magazine Onwership to the Monopoly

\begin{tabular}{|c|c|c|c|c|c|}
\hline & & \multicolumn{2}{|c|}{ One-Sided } & \multicolumn{2}{|c|}{ Two-Sided } \\
\hline & & Single & Monopoly & Single & Monopoly \\
\hline \multicolumn{6}{|l|}{ Readers } \\
\hline & Magazine 1 & 0.0033 & 0.0031 & 0.0032 & 0.0036 \\
\hline & Magazine 2 & 0.0089 & 0.0085 & 0.0090 & 0.0085 \\
\hline & Magazine 3 & 0.0015 & 0.0014 & 0.0014 & 0.0015 \\
\hline & Magazine 4 & 0.0011 & 0.0010 & 0.0010 & 0.0011 \\
\hline & Magazine 5 & 0.0050 & 0.0048 & 0.0050 & 0.0047 \\
\hline & Magazine 6 & 0.0030 & 0.0028 & 0.0030 & 0.0028 \\
\hline & Magazine 7 & 0.0024 & 0.0023 & 0.0022 & 0.0024 \\
\hline & Magazine 8 & 0.0032 & 0.0030 & 0.0029 & 0.0034 \\
\hline & Magazine 9 & 0.0040 & 0.0038 & 0.0040 & 0.0037 \\
\hline & Magazine 10 & 0.0042 & 0.0040 & 0.0042 & 0.0039 \\
\hline \multicolumn{6}{|l|}{ Advertisers } \\
\hline & Magazine 1 & & & 0.0733 & 0.0788 \\
\hline & Magazine 2 & & & 0.1746 & 0.1727 \\
\hline & Magazine 3 & & & 0.0435 & 0.0460 \\
\hline & Magazine 4 & & & 0.0144 & 0.0157 \\
\hline & Magazine 5 & & & 0.1957 & 0.1948 \\
\hline & Magazine 6 & & & 0.1468 & 0.1436 \\
\hline & Magazine 7 & & & 0.0636 & 0.0673 \\
\hline & Magazine 8 & & & 0.0395 & 0.0464 \\
\hline & Magazine 9 & & & 0.1419 & 0.1384 \\
\hline & Magazine 10 & & & 0.0930 & 0.0885 \\
\hline
\end{tabular}




\section{Appendix I: Alternative Specifications for the Advertiser Profit Function}

In this section I explore alternative specifications for the advertiser's profit function. The first alternative specification (Alt $I$ ) to consider is

$$
\pi_{i j t}^{B}=\alpha_{i}^{B} \omega_{j t}-p_{j t}^{B}
$$

where $\omega_{j t}$ denotes the magazine quality perceived by advertisers. Recall that in the original specification the magazine quality perceived by advertisers is at a per-reader level so that the advertising benefit for magazine $j$ is $\alpha_{i}^{B} \omega_{j t} n_{j t}^{A}$. In this alternative specification, the advertising benefit for magazine $j$ is $\alpha_{i}^{B} \omega_{j t}$, and $\omega_{j t}$ is a function of $n_{j t}$ and other magazine characteristics.

A nice feature of this specification is that advertisers' valuation on the number of readers can be directly estimated. One plausible function form for $\omega_{j t}$ is

$$
\omega_{j t}=\left(n_{j t}^{A}\right)^{\tau} \exp \left(\mathbf{w}_{j t} \gamma\right) \exp \left(e_{j t}\right)
$$

where $\omega_{j t}$ is positive only when $n_{j t}^{A}$ is non-zero, keeping an essential feature that magazines are valuable to advertisers only through readers. I treat $n_{j t}^{A}$ as an endogenous variable that can be correlated with $e_{j t}$ and use the number of readers in other magazine segments as instrumental variables. One may consider the original specification as fixing $\tau$ at 1 .

The second alternative specification $(A l t I I)$ to consider is

$$
\pi_{i j t}^{B}=\omega_{j t} n_{j t}^{A}-p_{j t}^{B}+r_{i j t}
$$

where $\omega_{j t}$ is the per-reader magazine quality and $r_{i j t}$ is an i.i.d. random variable distributed normal with mean zero. In this specification the mean valuation of a magazine is the same across advertisers, but each advertiser draws a random profit shock in each period.

An advertiser buys an advertising page in magazine $j$ only if $r_{i j t}>\omega_{j t} n_{j t}^{A}-p_{j t}^{B}$ such that a portion of advertisers who buy an advertising page in magazine $j$ is

$$
\frac{n_{j t}^{B}}{M_{B}}=\left(1-\Phi\left(\frac{\omega_{j t} n_{j t}^{A}-p_{j t}^{B}}{\sigma}\right)\right)
$$

where $\Phi($.$) is the cumulative distribution function of the standard normal distribution and \sigma$ is the variance of $r_{i j t}$.

The last alternative specification $(A l t I I I)$ is

$$
\pi_{i j t}^{B}=\omega_{j t}-p_{j t}^{B}+r_{i j t}
$$

where $\omega_{j}$ denotes the magazine quality. This specification combines the first and the second alternative specifications. $\omega_{j t}$ is a function of $n_{j t}$ and other magazine characteristics as in the first alternative specification, and the mean valuation of a magazine is the same across advertisers as in the second alternative specification.

Table 10 shows the GMM estimates of the advertiser-side magazine demand for the three 
alternative specifications. The variance parameter is fixed at 1.4, the same value as in the original specification. For comparison I put the original specification estimates in the second column (Base). The table shows that in the first alternative specification (Alt I) the coefficient on the log of the number of readers is positive and statistically significant. This means that the larger the reader base is, the larger the advertiser's revenue. This verifies the assumption of the original specification, but the larger-than-one coefficient implies that the advertiser's revenue increases with the reader base much faster than in the original specification.

The average magazine quality implied by the estimates of the magazine dummy variables (not reported in the table) is slightly different compared to the original specification. The five highest quality and the four lowest quality magazines are the same in both specifications, but the magazines that are ranked the $11^{\text {th }}$ and the $8^{\text {th }}$ respectively in the original specification are ranked the $6^{\text {th }}$ and the $13^{\text {th }}$ in the alternative specification.

There are more drastic changes in the average magazine quality in the second alternative specification (Alt II). For example, the second highest quality magazine in the base specification is ranked the 10 th, and the $13^{\text {th }}$ ranked magazine in the original specification is ranked the $4^{\text {th }}$. However, the highest quality magazine and the two lowest quality magazines do not change.

Interestingly, the magazine quality ranking is exactly the same except for one magazine between the second and the third alternative specifications. However, the coefficient on the log of the number of readers is close to zero and statistically insignificant in the third alternative specification (Alt III). It is in sharp contrast with the result of the first alternative specification and misleadingly implies that advertisers do not put much value on the number of readers their advertising can reach. This suggests that putting the advertiser heterogeneity additively in the profit function may not be a correct modeling choice.

\section{Appendix II: Estimation in the Two-Sided Single-Homing Model}

In the two-sided single-homing model advertisers choose only one magazine for advertising. They make a magazine choice to maximize their profits. Advertiser $i$ 's profit function of advertising in magazine $j$ is

$$
\pi_{i j}^{B}=R_{i j}-p_{j}^{B}
$$

where $R_{i j}$ is the advertiser's revenue and $p_{j}^{B}$ is a per-page advertising price the magazine charges. Assuming that the advertiser's revenue is a linear function of magazine characteristics including the market share on the reader side,

$$
\pi_{i j}^{B}=\mathbf{x}_{j} \boldsymbol{\beta}^{B}-p_{j}^{B}+\xi_{j}^{B}+\varepsilon_{i j}^{B}
$$

where $\mathbf{x}_{j}$ includes observed magazine characteristics, $\xi_{j}^{B}$ denotes the mean effect of unobserved magazine characteristics and demand shocks on the advertiser's revenue and $\varepsilon_{i j}^{B}$ is an i.i.d. idiosyncratic profit shock which I assume is distributed type I extreme value.

A system of demand equations to estimate is equations (16) and (17) in section 3. The only difference is that the price coefficient for advertisers is set to -1 . The share of readers is an endogenous variable and I use the same type of instrumental variables as in estimating the competitive bottleneck model. I divide both the copy price and the advertising price by 10,000. 
Otherwise, the exponential function in the advertiser-side market share blows up. Dividing the copy price does not affect demand estimates other than scaling up the price coefficient. Also, I make the market size on the advertiser side larger than the sum of advertising pages across magazines in a given period to be consistent with the assumption in the two-sided single-homing model that advertisers choose only one magazine.

Table 11 shows estimation results in the two-sided single-homing model. The reader-side estimates using the system IV and the GMM estimation techniques are statistically significant and their magnitudes are similar to those in table 5 except for the advertising share variable. This difference mainly comes from using the advertising share variable rather than the number of advertising pages. All coefficients, nevertheless, change in the same direction as in table 5. On the advertising side the reader share variable is added in estimation. Its coefficient is positive, meaning that advertisers appreciate a larger reader base, and its magnitude goes down with instrumental variables, implying that it is positively correlated with demand shocks. Recall that the price coefficient is fixed at -1 so the reader share variable is the only endogenous variable.

One thing to notice is that the reader share coefficient is about four times larger than the advertising share coefficient. Recall that in the two-sided single-homing model, platforms charge a lower price to a smaller size group if the two group's valuation of the other group is the same. However, the data show that advertisers, the smaller size group, pay much higher prices than readers do. The larger reader share coefficient resolves this inconsistency by showing that advertisers appreciate readers more than readers appreciate advertisers.

These demand estimates seem to suggest that the two-sided single-homing model can be also used to describe the media advertising. In fact, the magazines usually charge below-cost copy prices to readers and make profits from advertisers in this model, as advertisers' appreciation of readers is much greater than readers' appreciation of advertisers. However, a loss on the reader side is much less adequately compensated by a profit on the advertiser side. That is because magazines compete to attract advertisers instead of behaving as monopolists towards them. Moreover, magazines with larger reader bases make smaller profits. This is in sharp contrast to the result in the competitive bottleneck model where magazines with larger reader bases are able to earn higher profits from advertisers. ${ }^{21}$ These results render support to using the competitive bottleneck model in describing magazine advertising.

\footnotetext{
${ }^{21}$ The coefficient correlation between the two sides' markups is -0.92 in the competitive bottleneck model while it is 0.18 in the two-sided single-homing model.
} 
Table 10: GMM Estimation with Alternative Advertising Profit Functions

\begin{tabular}{ccccc}
\hline \hline \multirow{2}{*}{ Advertiser Side } & Base & Alt I & Alt II & Alt III \\
\hline \multirow{2}{*}{ Constant } & $0.919^{*}$ & -2.805 & $2.178^{*}$ & 1.191 \\
& $(0.230)$ & $(1.682)$ & $(0.096)$ & $(1.004)$ \\
& & & & \\
Content Page & $-0.110^{*}$ & $-0.111^{*}$ & $-0.098^{*}$ & $-0.099^{*}$ \\
& $(0.011)$ & $(0.013)$ & $(0.006)$ & $(0.007)$ \\
$\log$ (\#Readers) & & & & \\
& & $1.326^{*}$ & & 0.090 \\
& & $(0.158)$ & & $(0.095)$
\end{tabular}

The market size for readers is set to 40 million and the market size for advertisers to 200 . The magazine fixed effects and the time effects are included in all estimations.

Standard errors are reported in parenthesis.

*significant at the $5 \%$ level. 
Table 11: Demand Estimation in the Two-Sided Single-Homing Model

\begin{tabular}{|c|c|c|c|c|}
\hline Variable & & OLS & System IV & GMM \\
\hline \multirow[t]{4}{*}{ Readers } & Constant & $\begin{array}{c}-7.001^{*} \\
(0.232)\end{array}$ & $\begin{array}{c}-5.500^{*} \\
(0.494)\end{array}$ & $\begin{array}{l}-5.092^{*} \\
(0.471)\end{array}$ \\
\hline & Copy Price & $\begin{array}{c}-0.020 \\
(0.012)\end{array}$ & $\begin{array}{c}-0.122^{*} \\
(0.028)\end{array}$ & $\begin{array}{c}-0.137^{*} \\
(0.027)\end{array}$ \\
\hline & $\begin{array}{c}\text { Ads Share } \\
\text { (in \%) }\end{array}$ & $\begin{array}{l}0.465^{*} \\
(0.042)\end{array}$ & $\begin{array}{c}0.875^{*} \\
(0.113)\end{array}$ & $\begin{array}{l}0.799^{*} \\
(0.110)\end{array}$ \\
\hline & Content Page & $\begin{array}{c}0.063^{*} \\
(0.007)\end{array}$ & $\begin{array}{l}0.070^{*} \\
(0.008)\end{array}$ & $\begin{array}{l}0.063^{*} \\
(0.007)\end{array}$ \\
\hline \multirow[t]{3}{*}{ Advertisers } & Constant & $\begin{array}{c}-2.362^{*} \\
(0.261)\end{array}$ & $\begin{array}{c}-2.244^{*} \\
(0.382)\end{array}$ & $\begin{array}{c}-2.224^{*} \\
(0.368)\end{array}$ \\
\hline & $\begin{array}{l}\text { Reader Share } \\
\quad \text { (in \%) }\end{array}$ & $\begin{array}{l}4.814^{*} \\
(0.203)\end{array}$ & $\begin{array}{l}3.657^{*} \\
(0.607)\end{array}$ & $\begin{array}{l}2.857^{*} \\
(0.498)\end{array}$ \\
\hline & Content Page & $\begin{array}{c}-0.121^{*} \\
(0.016)\end{array}$ & $\begin{array}{c}-0.117^{*} \\
(0.015)\end{array}$ & $\begin{array}{c}-0.126^{*} \\
(0.014)\end{array}$ \\
\hline
\end{tabular}

The market size for readers is set to 40 million and the market size for advertisers to 5,000. The magazine fixed effects and the time effects are included in all estimations.

Standard errors are reported in parenthesis.

*significant at the $5 \%$ level. 